\title{
Function of BCLAF1 in human disease (Review)
}

\author{
ZONGDONG YU ${ }^{1,2^{*}}$, JIE ZHU $^{1,2^{*}}$, HAIBIAO WANG ${ }^{2}$, HONG LI $^{1,2}$ and XIAOFENG JIN ${ }^{1,2}$ \\ ${ }^{1}$ Department of Hepatobiliary and Pancreatic Surgery, Ningbo Medical Center of LiHuiLi Hospital, Ningbo University, \\ Ningbo, Zhejiang 315040; ${ }^{2}$ Department of Biochemistry and Molecular Biology, \\ Zhejiang Key Laboratory of Pathophysiology, Medical School of Ningbo University, \\ Ningbo, Zhejiang 315211, P.R. China
}

Received July 5, 2021; Accepted September 22, 2021

DOI: $10.3892 / \mathrm{ol} .2021 .13176$

\begin{abstract}
Originally identified as a regulator of apoptosis and transcription, B-cell lymphoma-2-associated transcription factor 1 (BCLAF1) has since been shown to be associated with a multitude of biological processes, such as DNA damage
\end{abstract}

Correspondence to: Professor Xiaofeng Jin or Professor Hong Li, Department of Hepatobiliary and Pancreatic Surgery, Ningbo Medical Center of LiHuiLi Hospital, Ningbo University, 57 XingNing Road, Ningbo, Zhejiang 315040, P.R. China

E-mail: jinxiaofeng@nbu.edu.cn

E-mail: 1019300034@qq.com

*Contributed equally

Abbreviations: BCLAF1, B-cell lymphoma-2-associated transcription factor 1; RS rich domain, arginine-serine rich domain; bZIP domain, basic-leucine zipper domain; DDR, DNA damage response; SMYD3, histone methyltransferase SET and MYND domain-containing protein 3; miR, microRNA; DNA-PKC, DNA-protein kinase C; RNP, ribonucleoprotein; DLBCL, diffuse large B-cell lymphoma; HIF-1 $\alpha$, hypoxia inducible factor- $1 \alpha$; HCC, hepatocellular carcinoma; H3K56, histone 3 lysine 56 residues; HDACi, histone deacetylase inhibitor; CNS, conserved non-coding sequences; EDMD, Emery-Dreifuss muscular dystrophy; AML, acute myelocytic leukemia; KSHV, Kaposi's sarcoma-associated herpesvirus; HCMV, human cytomegalovirus; Hsp90 $\alpha$, heat shock protein 90 $\alpha$; CPE-TP53, TP53 core promoter element; IR, ionizing radiation; DSB, double-strand break; $\gamma \mathrm{H} 2 \mathrm{AX}, \mathrm{H} 2 \mathrm{AX}$ phosphorylated on serine 139; IncRNA NEAT1, long non-coding RNA nuclear enrichment-rich transcription factor 1; 5-Fu, 5-fluorouracil; $\mathrm{BC}$, bladder cancer; H3K4, histone H3 lysine 4; Bcl-2, B-cell lymphoma-2; LC, lung cancer; NHEJ, non-homologous end-joining; dsDNA, double-stranded DNA; FHL1, four-and-a-half LIM protein 1; NSCLC, non-small cell lung cancer; USP22, ubiquitin-specific peptidase 22; MM, multiple myeloma; DISC, death-inducing signaling complex; CRC, colorectal cancer; L isoform, large protein of 920 amino acids; CK, compound K; PRV, pseudorabies virus; HSV-1, herpes simplex virus type 1; HPV16, human papillomaviruses 16; I/R injury, ischemia-reperfusion injury; PD-L1, programmed cell death ligand 1; 3'UTR, 3'-untranslated region

Key words: BCLAF1, apoptosis, transcription, tumorigenesis, autophagy response, splicing and processing of pre-mRNA, T-cell activation, lung development, muscle cell proliferation and differentiation, autophagy, ischemia-reperfusion injury, and viral infection. In recent years, an increasing amount of evidence has shown that BCLAF1 acts as either a tumor promoter or tumor suppressor in tumorigenesis depending on the cellular context and the type of cancer. Even in the same tumor type, BCLAF1 may have opposite effects. In the present review, the subcellular localization, structural features, mutations within BCLAF1 will be described, then the regulation of BCLAF1 and its downstream targets will be analyzed. Furthermore, the different roles and possible mechanisms of BCLAF1 in tumorigenesis will also be highlighted and discussed. Finally, BCLAF1 may be considered as a potential target for cancer therapy in the future.

\section{Contents}

1. Introduction

2. Subcellular localization of BCLAF1

3. Structural features of BCLAF1

4. Expression and mutations of BCLAF1 in cancer

5. Regulation of BCLAF1 expression and function

6. Downstream targets regulated by BCLAF1

7. BCLAF1, HIF- $1 \alpha$ and NF- $\kappa B$ in cancer

8. Physiological function of BCLAF1

9. Roles of BCLAF1 in human cancer

10. BCLAF1 and RT

11. Roles of BCLAF1 in virus replication

12. Roles of BCLAF1 in cardiac I/R injury

13. Conclusion

\section{Introduction}

BCLAF1 was originally identified as a binding protein that interacted with adenoviral Bcl-2 homolog E1B19K, and served as an inducer of apoptosis and suppressor of transcription (1). Subsequent studies have shown that BCLAF1 also played a key role in a wide range of biological processes, including pre-mRNA splicing and processing (2-6), DNA damage response (DDR) (3,4,7-11), lung development (12), viral infection (13-16), muscle cell proliferation and differentiation (17-20), 
autophagy $(21,22)$, ischemia-reperfusion (I/R) injury (23), and T-cell activation $(12,24,25)$.

BCLAF1 primarily localizes to the dot-like structures throughout the nucleus and at a lower number in the cytoplasm (1). The salient features of the BCLAF1 structure include an arginine-serine (RS) rich domain, a basic-leucine zipper (bZIP) domain located within the RS domain, and a MYB DNA-binding domain (Fig. 1A) $(1,12)$. Studies have shown that proteins containing the RS domain are usually involved in post-transcriptional events, such as pre-mRNA splicing and processing (26-28). In addition, the MYB DNA-binding and bZIP domains have also been found to be required for the transcriptional regulatory function of BCLAF1 $(29,30)$. Therefore, these structural features are necessary for the regulatory function of BCLAF1 at the transcriptional and post-transcriptional levels. For example, BCLAF1 was found to be associated with apoptosis, DDR and tumorigenesis by activating the transcription of its downstream target genes [such as TP53, Bax, HIF-l $\alpha$ and long non-coding (lnc) RNA NEAT1] or inhibiting the transcription of its downstream genes (such as MDM2) (7,9,30-32). In addition, BCLAF1 also exerted important functions in the cell cycle, DDR, tumorigenesis and T-cell differentiation by regulating pre-mRNA splicing and mRNA processing $(4,5,30,33,34)$. By contrast, BCLAF1 serves as a downstream target, regulated by numerous molecules at the transcriptional, translational and post-translational levels, thus influencing several biological processes. For example, the type III histone deacetylase, Sirt1, histone methyltransferase SET and MYND domain-containing protein 3 (SMYD3) and NF- $\mathrm{KB}$ have all been associated with tumorigenesis by regulating the transcription of BCLAF1 $(8,22,24,35)$. Furthermore, micro (mi)RNA-194-5p exerted its anticancer activity by repressing the translation of BCLAF1 (36). Furthermore, DNA-protein kinase C (DNA-PKC) was associated with DDR and apoptosis by directly phosphorylating serine $^{151}$ and tyrosine ${ }^{150}$ in the RS domain of BCLAF1 (Fig. 1B-a) (7). Notably, increasing evidence has demonstrated that BCLAF1 was associated with tumorigenesis as either a tumor promotor $(11,22,30,31,34,37-42)$ or a tumor suppressor $(7,21,32,35,43)$ in a context-dependent manner. In addition to for tumorigenesis and viral replication, BCLAF1 has also been associated with cardiac I/R injury (23). A previous study showed that BCLAF1 could promote the apoptosis of cardiomyocytes via activating apoptosis regulatory proteins such as TP53 and BAX, and then aggravated the cardiac I/R injury (Fig. 1B-k) (23).

In consideration of recent advances in the understanding of multiple biological functions of BCLAF1, particularly in tumorigenesis, BCLAF1 exerts an important role in different human cancers; therefore, the aim of the present review was to introduce the subcellular localization, structural features, expression and mutations, regulation, biological functions and pathological functions of BCLAF1, then describe the roles of BCLAF1 in tumorigenesis. Lastly, BCLAF1 may represent a potential cancer therapeutic target in the future.

\section{Subcellular localization of BCLAF1}

BCLAF1 is predominantly located in the nuclear dot-like structures and secondarily located in the cytoplasm (1).
Previous studies have discovered that the diverse biological functions of BCLAF1 have been associated with its different cellular locations. For example, the anti-apoptotic members of the Bcl-2 family inhibited the pro-apoptotic effect of BCLAF1 by isolating BCLAF1 in the cytoplasm (1). In another study, in the HeLa cell line, which were induced to undergo apoptosis, BCLAF1 relocated from the nuclear dot-like structures to a position near the nuclear envelope (18). Similarly, Lee et al (7) also observed the same translocation phenomenon of BCLAF1 when the $293 \mathrm{~T}$ cell line was exposed to high-dose radiation. Furthermore, a recent report showed that the nuclear translocation of BCLAF1 significantly increased following the induction of cardiac I/R injury (23).

\section{Structural features of BCLAF1}

The BCLAF1 gene is located on human chromosome 6q23.3, encoding 17 transcription variants of different isoforms (44). The L isoform of BCLAF1 (a large protein containing 920 amino acids) will be described. BCLAF1 contains multiple domains, including a N-terminal RS domain, which contains a bZIP domain and a C-terminal MYB DNA-binding domain (Fig. 1A) $(1,12)$. The RS domain is involved in the biogenesis and splicing of pre-mRNA (26-28), and the formation of the ribonucleoprotein (RNP) complex, which is an important part of the pre-mRNA spliceosome $(6,45,46)$. Thus, BCLAF1 also exerts its post-transcriptional splicing function by participating in the formation of the spliceosome (2-6). It has been found that the RS domain can mediate protein-protein interactions, such as RNP, snRNP U1-70K and the splicing factor, U2AF $(47,48)$. Notably, three of the five protein binding sites, that interact with BCLAF1, are located in the RS domain $(7,30,39)$, suggesting that interactions between BCLAF1 and other proteins may be mediated by the RS domain; however, this requires further research. It is well-known that the bZIP and MYB DNA-binding domains are characteristic components of eukaryotic transcription factor families (49-51). These structural features of BCLAF1 allow it to act as a transcription factor and mRNA splicing factor, at the transcriptional and post-transcriptional levels, to participate in the regulation of expression of downstream target genes (4,5,7,9,26-28,30-34).

\section{Expression and mutations in BCLAF1 in cancer}

To the best of our knowledge, the expression level and mutations in BCLAF1 in human normal tissues and tumor tissues have not been systematically studied or summarized in the literature, particularly the mutations in BCLAF1. Therefore, the expression level of BCLAF1 in human normal and cancer tissues, and the mutation status of BCLAF1 in patients with malignant tumors was found using the Human Protein Atlas database (https://www.proteinatlas.org/ENSG00000029363-BCLAF1) (Fig. 2) and the International Cancer Genome Consortium database (ICGC; https://dcc.icgc.org/genes/ENSG00000029363) (Table I), respectively. In addition, survival analysis was performed using the GEPIA2 database (http://gepia2. cancer-pku.cn/\#survival) with Kaplan-Meier analysis (Fig. 3).

According to the data from the Human Protein Atlas database, BCLAF1 was expressed at different levels in all normal tissues (Fig. 2A) and most cancer tissues (Fig. 2B), and 


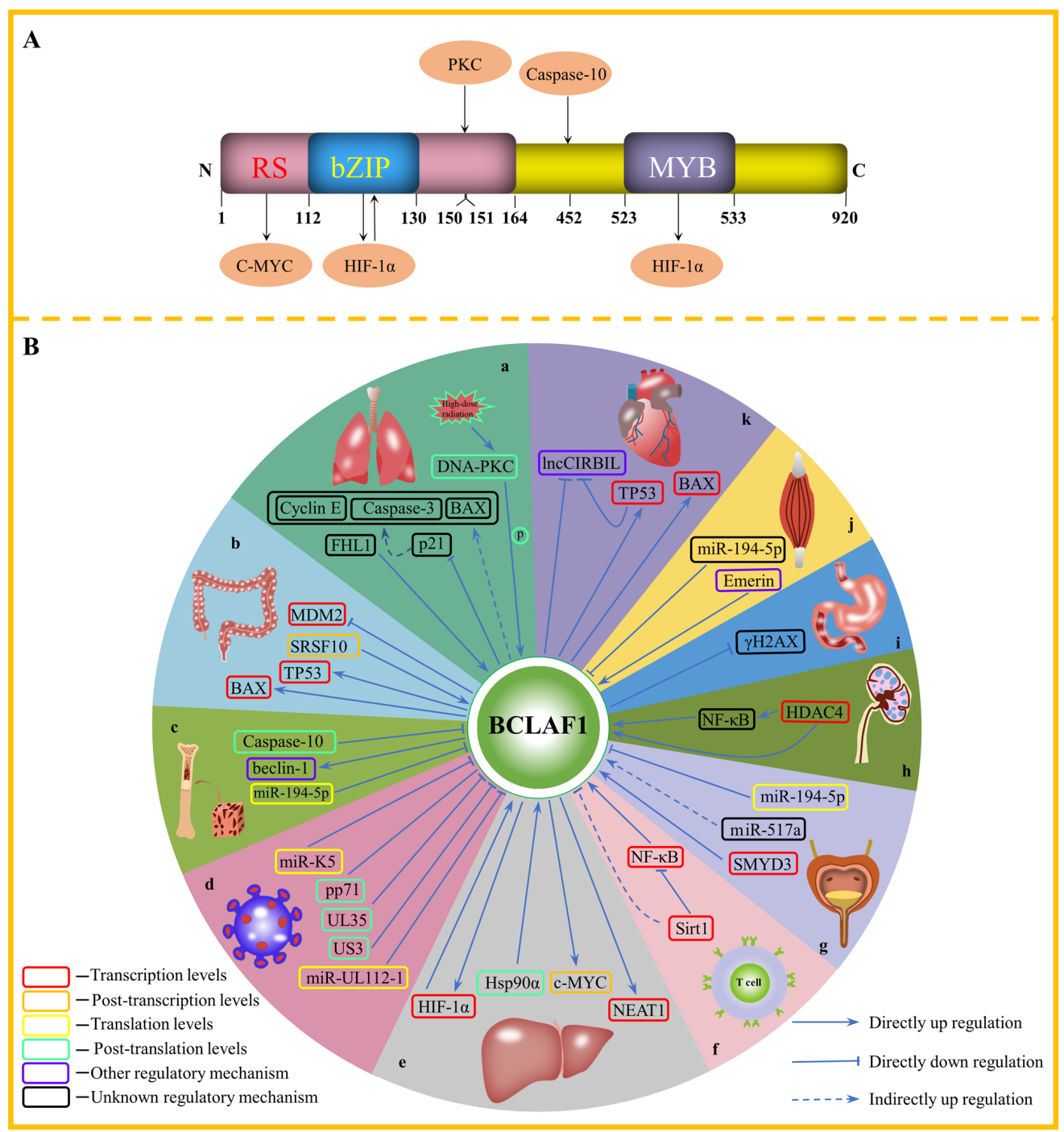

Figure 1. (A) Structure of the BCLAF1 protein and the molecules that interact with BCLAF1 and their binding sites. The structure of BCLAF1 contains multiple domains, including an N-terminal RS domain, which contains the bZIP domain, and a C-terminal MYB DNA-binding domain. The molecules that interact with BCLAF1 include c-Myc, HIF-1 $\alpha$, PKC and caspase-10. BCLAF1 can protect mature $c-M y c$ mRNA from degradation by the RS domain in HCC. In addition, the bZIP domain of BCLAF1 can bind to HIF-1 $\alpha$ and promote transcription of each other in HCC. Furthermore, BCLAF1 reduces HIF-1 $\alpha$ ubiquitination and subsequent degradation via its MYB domain, binding to the helix-loop-helix domain of HIF-1 $\alpha$. In addition, DNA-PKC is involved in the DNA damage response and apoptosis by directly phosphorylating serine $\mathrm{e}^{151}$ and tyrosine $\mathrm{S}^{150}$ in the RS domain. Furthermore, caspase-10 protects MM cells from autophagic death induced by BCLAF1 via cleavage of the aspartic acid at position 452. (B) The role of BCLAF1 in different diseases and pathological processes. (a) Under high-dose radiation, DNA-PKC is activated and phosphorylates BCLAF1, which then initiates DNA damage repair. BCLAF1 antagonizes p21-dependent downregulation of cyclin E expression and inhibition of p21-dependent pro-apoptotic factors, caspase-3 and BAX by repressing the expression level of p21; however, downregulation of BCLAF1 levels may contribute to the tumorigenesis of LC. Phosphorylated FHL1 can interact with BCLAF1 and promote its expression, then promote the proliferation of the LC cells. (b) BCLAF1 mediates the apoptosis of colon cancer cells by activating the transcription of TP53 and BAX, and inhibiting the transcription of MDM2. Splicing factor, SRSF10 is involved in the post-transcriptional splicing of BCLAF1 and forms the L isoform, thereby promoting the progression of colorectal cancer. (c) miR-194-5p binds to the 3'-UTR of BCLAF1 and inhibits the translation of BCLAF1 in acute myelocytic leukemia. Caspase-10 protects MM cells from autophagic death induced by BCLAF1 by phosphorylating aspartic acid at position 452, which leads to BCLAF1 replacing beclin-1, thereby promoting autophagy. (d) miR-K5 and miR-UL112-1 inhibit the translation of BCLAF1 by binding to its 3'-UTR. After HCMV and PRV infect host cells, they promote the degradation of BCLAF1 protein by releasing viral proteins, pp71, UL35 and US3. (e) BCLAF1 can activate the transcription of HIF-1 $\alpha$ and NEAT1 and promote the occurrence and development of HCC. At the same time, HIF-1 $\alpha$ can also activate the transcription of BCLAF1 in HCC. Hsp90 $\alpha$ interacts with BCLAF1 and inhibits its degradation by the proteasome, and BCLAF1 contributes to the occurrence and development of HCC by protecting mature oncogene, c-Myc mRNA from degradation. (f) Sirt1 binds to NF-kB, translocates to the BCLAF1 promoter and deacetylates histone H3K56 to inhibit the NF-kB-dependent transcription of BCLAF1, ultimately inhibiting the activation of T cells. (g) miR-517a may inhibit cell proliferation and promote cell apoptosis by indirectly upregulating the expression level of BCLAF1 in BC. miR-194-5p binds to the 3'-UTR of BCLAF1 and inhibits the translation of BCLAF1, thereby repressing the malignant phenotype of BC. SMYD3 activates the transcription of BCLAF1 by increasing the methylation of H3K4, and SMYD3 promotes the progression of BC by targeting BCLAF1 to activate autophagy. (h) HDAC4 inhibits the transcription of BCLAF1 by deacetylating the BCLAF1 promoter. HDAC4 may indirectly inhibit the expression of BCLAF1 by upregulating NF-kB. (i) Gastric cancer cells with BCLAF1 knocked down display decreased cell proliferation and increased basal $\gamma \mathrm{H} 2 \mathrm{AX}$, and are more vulnerable to I/R-induced DNA damage and apoptosis. (j) An Emerin mutation disrupts the interaction between Emerin and BCLAF1, which in turn leads to abnormal muscle cell proliferation and differentiation. miR-194-5p promoted the myogenic differentiation of mouse muscle cells by downregulating BCLAF1. (k) Translocation of BCLAF1 to the nucleus activates the transcription of TP53 and BAX, which promotes the apoptosis of cardiomyocytes induced by I/R. IncCIRBIL binds to the BCLAF1 protein in the cytoplasm of cardiomyocytes to prevent its translocation to the nucleus, thus repressing the cardiac I/R injury. BCLAF1, B-cell lymphoma-2-associated transcription factor 1; RS rich domain, arginine-serine rich domain; bZIP domain, basic-leucine zipper domain; HIF-1 $\alpha$, hypoxia inducible factor-1 $\alpha$; PKC, protein kinase C; HCC, hepatocellular carcinoma; MM, multiple myeloma; FHL1, four-and-a-half LIM protein 1; miR, microRNA; UTR, untranslated region; HCMV, human cytomegalovirus; PRV, pseudorabies virus; NEAT, nuclear enrichment-rich transcription factor 1; BC, bladder cancer; SMYD3, histone methyltransferase SET and MYND domain-containing protein 3; HDAC, histone deacetylase; $\gamma \mathrm{H} 2 \mathrm{AX}, \mathrm{H} 2 \mathrm{AX}$ phosphorylated on serine 139; I/R injury, ischemia-reperfusion injury; lnc, long non-coding. 


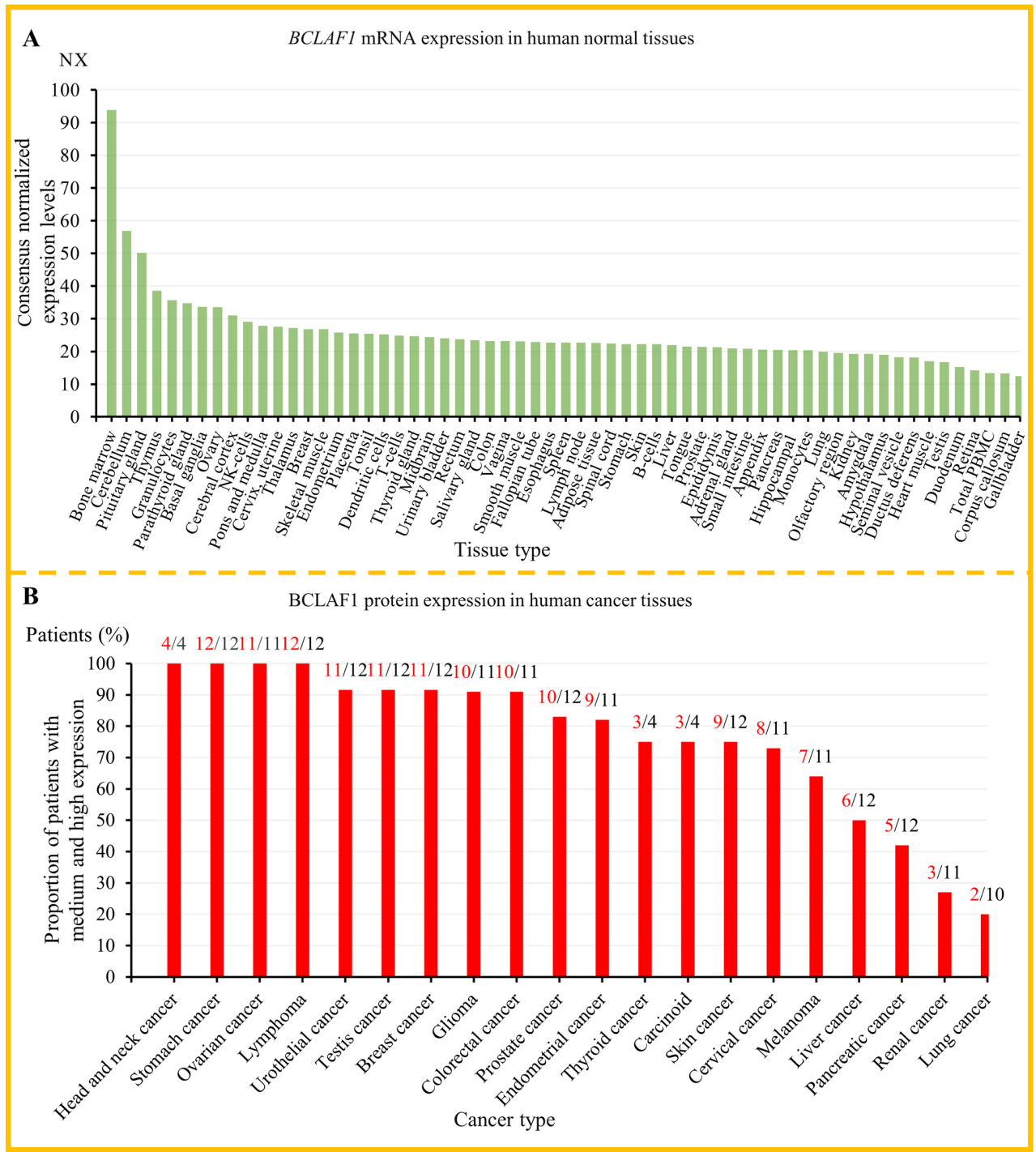

Figure 2. (A) BCLAF1 mRNA expression in human normal tissues. The expression levels are shown as consensus NX levels in 55 tissue types and 6 blood cell types. (B) BCLAF1 protein expression in human cancer tissues. The expression levels are shown as the proportion of patients with medium and high expression of BCLAF1 in cancer tissues from immunohistochemistry. NX, normalized expression.

$\mathbf{A}$

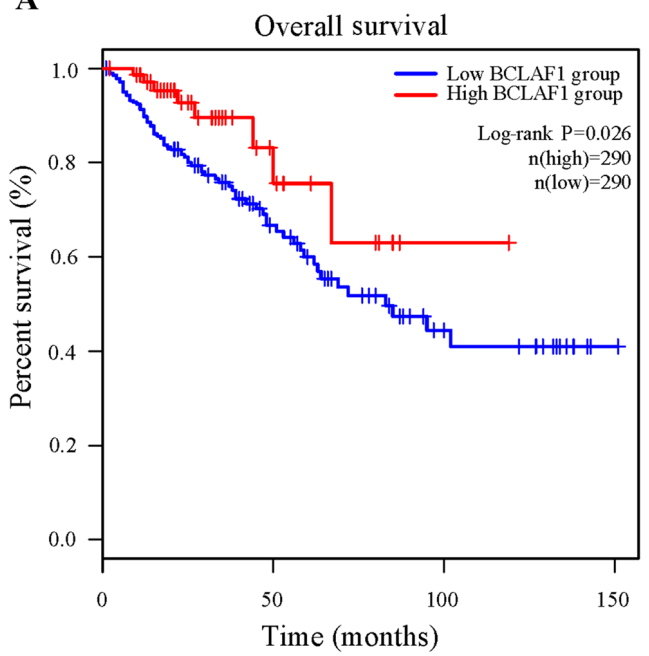

B

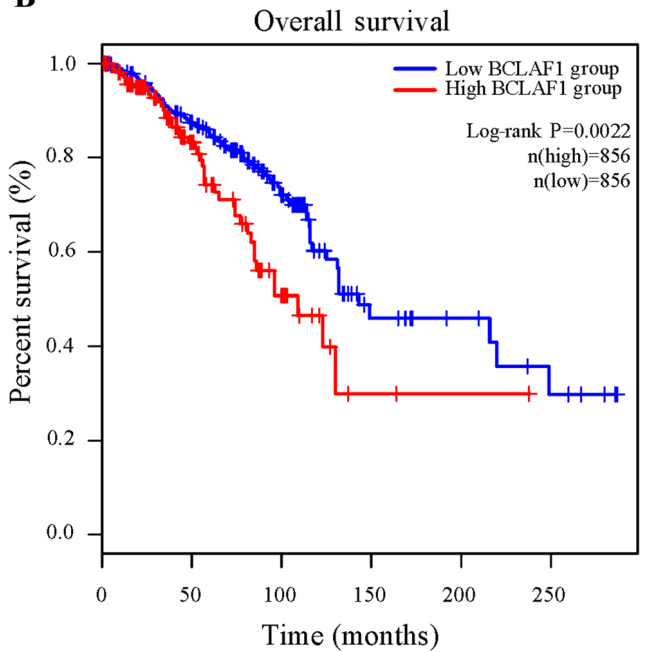

Figure 3. Survival analysis of BCLAF1 in colorectal cancer and breast cancer. (A) Survival analysis between BCLAF1 expression and prognosis in patients with colorectal cancer. Kaplan-Meier survival curve showed that high $B C L A F 1$ mRNA expression levels was associated with favorable overall survival in patients with colorectal cancer. (B) Survival analysis between BCLAF1 expression and prognosis in patients with breast cancer. Kaplan-Meier survival curve showed that high BCLAF1 mRNA expression level was associated with poor overall survival in patients with breast cancer. 


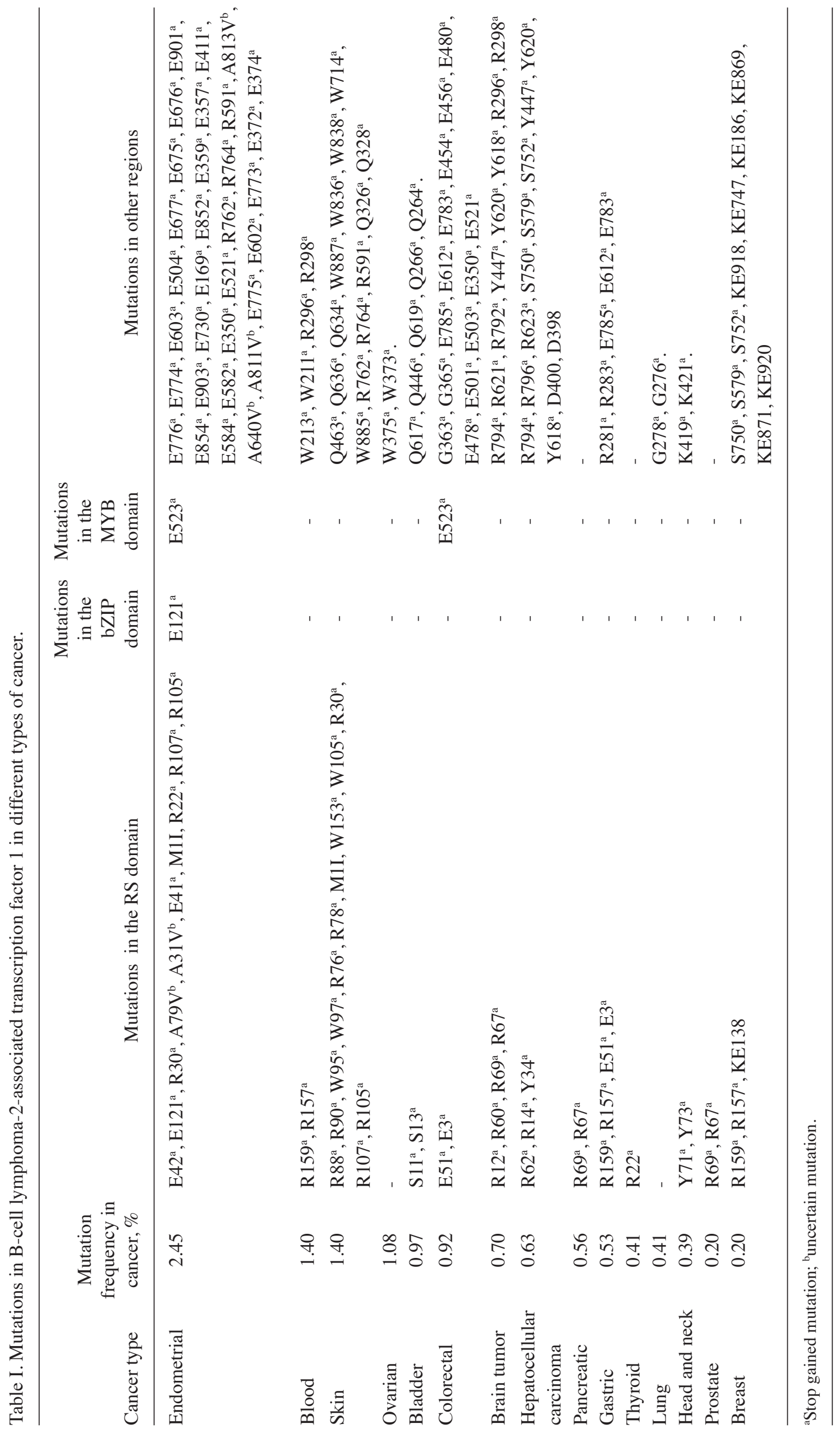


its expression has low tissue specificity and tumor specificity. In addition, survival analysis, into the association between the expression level of BCLAF1 in multiple types of cancer and the survival rate of patients, indicated that BCLAF1 could not be used as a clear prognostic marker in most cancers, except for colorectal cancer and breast cancer (Fig. 3). In colorectal cancer, the high mRNA expression level of BCLAFl was associated with favorable overall survival rate in 290 patients and low mRNA expression level of BCLAF1 was associated with poor overall survival in 290 patients $(\mathrm{P}=0.026)$ (Fig. 3A). In breast cancer, the high mRNA expression level of $B C L A F 1$ was associated with poor overall survival in 856 patients and the low mRNA expression level of BCLAF1 was associated with favorable overall survival rate in 856 patients $(\mathrm{P}=0.0022)$ (Fig. 3B).

Furthermore, the ICGC database showed that different mutations were found in BCLAF1 in various types of cancer. The mutations were primarily located in the RS domain and other regions (sites other than the known domains of BCLAF1), while there were fewer mutations in the bZIP and the MYB domains (Table I). In addition, the majority of the mutations in BCLAF1 were stop-gain mutations, with fewer frameshift and start-loss mutations (a subtype of non-sense mutations) (Table I). The mutations in BCLAF1 have been detected in numerous cancer samples; however, the clinical significance is unknown; therefore, additional research is required.

Taken together, from the analysis of data from TCGA and ICGC, it can be concluded that the existing pathological evidence (human cancer specimens) is still insufficient to clarify the specific function of BCLAF1 in tumorigenesis. It is necessary to further expand the sample size to obtain more evidence, such as physiological evidence (animal models) and biochemical evidence (upstream and downstream molecules of BCLAF1).

\section{Regulation of BCLAF1 expression and function}

The expression and function of BCLAF1 is affected by numerous processes at multiple levels of regulation, including the transcriptional, post-transcriptional, translational and post-translational levels. A previous study showed that a NF- $\mathrm{BB}$ binding site was found in the promoter region of BCLAF1 and $\mathrm{NF}-\kappa \mathrm{B}$ activates its transcription by binding to the promoter of BCLAF1 in T-cell activation (24). Similarly, another study also confirmed this process in senescent cells induced by the chemotherapeutic agent, doxorubicin (8). However, Li et al (35) found the opposite results. They demonstrated that the mRNA expression level of BCLAF1 was increased in the diffuse large B-cell lymphoma (DLBCL) cell lines treated with the NF- $\kappa$ B inhibitor, Bay11-7082, indicating that NF- $\kappa B$ may downregulate the expression level of BCLAF1; however, the specific mechanism involved requires further investigation.

Furthermore, hypoxia inducible factor- $1 \alpha$ (HIF-1 $\alpha)$ has been shown to bind to the promoter region of BCLAF1 and directly activate its transcription in hepatocellular carcinoma (HCC) (Fig. 1A and B-e) (30). In addition to regulating the expression level of BCLAF1, through the combination of transcription factors and promoters, epigenetic modifications have also been found to be involved in the regulation of BCLAF1 $(22,24,35)$. In one study it was found that Sirt1 repressed BCLAF1 transcription by deacetylating the histone 3 lysine 56 residues (H3K56) on conserved non-coding sequences (CNS) 3 and CNS4 in the promoter region and the loss of Sirt1, using RNA interference resulted in increased transcription of BCLAF1, which was responsible for T-cell activation (Fig. 1B-f) (24). Specifically, Sirt1 was combined with Rel-A (a subunit of NF- $\kappa$ B) and recruited to the BCLAF1 promoter, which initiated the deacetylation modification of BCLAF1 (Fig. 1B-f) (24). Furthermore, in another study, a HDAC inhibitor (HDACi), LMK-235 upregulated BCLAF1 mRNA expression and promoted apoptosis in DLBCL (35) Mechanistically, LMK-235 upregulated BCLAF1 expression and BCLAF1-mediated apoptosis by inhibiting the NF- $\kappa \mathrm{B}$ pathway (35). In addition, Shen et al (22) confirmed that the histone methyltransferase, SMYD3 physically interacted with the promoter of BCLAF1 and upregulated its mRNA expression by the increase in the dimethylation and trimethylation of histone $\mathrm{H} 3$ lysine 4 (H3K4) at the BCLAF1 locus (Fig. 1B-g). In addition, Zhou et al (34) demonstrated that the splicing factor, SRSF10 was a direct upstream regulatory molecule of BCLAF1 and participated in the production of the BCLAF-L isoform via the post-transcriptional splicing of BCLAF1 in colorectal cancer (Fig. 1B-b).

miRNAs are small non-coding RNAs, that negatively regulate gene expression (52). BCLAF1 has also been found to be regulated as a direct downstream target of miR-194-5p, miR-K5 and miR-UL112-1 $(13,15,20,36,38)$. Dell'Aversana et al (38) discovered that miR-194-5p binds the 3'-untranslated region (3'-UTR) of BCLAF1 to suppress its gene expression, proving that the dysregulation of this regulatory pathway results in the occurrence of acute myelocytic leukemia (AML) (Fig. 1B-c). Similarly, two other studies reported that miR-194-5p could inhibit the translation of BCLAF1 in bladder cancer and muscle cells (Fig. 1B-g and -j) (20,36). Furthermore, similar inhibitory effects of miRNAs on BCLAF1 have also been observed in viral infections $(13,15)$. For example, miR-K5, encoded by Kaposi's sarcoma-associated herpes virus (KSHV) (15) and miR-UL112-1, encoded by human cytomegalovirus (HCMV) (13) both inhibited the translation of BCLAF1 by binding to its 3'-UTR (Fig. 1B-d). In addition, Liu et al (9) showed that after induction of DNA damage, PKC $\delta$ and BCLAF1 formed a complex to occupy TP53 core promoter element (CPE-TP53) and promoted TP53-mediated apoptosis in response to DNA damage. A subsequent study further validated this conclusion. Lee et al (7) indicated that DNA-PKC was associated with DDR and apoptosis by directly phosphorylating serine ${ }^{151}$ and tyrosine ${ }^{150}$ in the RS domain in BCLAF1 (Fig. 1A and B-a). Similarly, a recent study proved that the phosphorylation of BCLAF1 at serine ${ }^{290}$ participated in DDR mediated by $\mathrm{H} 2 \mathrm{AX}$ phosphorylated on serine ${ }^{139}(\gamma \mathrm{H} 2 \mathrm{AX})(11)$. Lastly, heat shock protein $90 \alpha(\mathrm{Hsp} 90 \alpha)$ was found to bind to BCLAF1 and stabilize its protein structure, thus preventing BCLAF1 from degradation via the ubiquitin-proteasome system (UPS) in HCC (Fig. 1B-e) (39).

It is worth noting that 20 high-frequency transcription factors, that might bind to the BCLAF1 promoter region were predicted using the PROMO database (http://alggen.lsi.upc. es/cgi-bin/promo_v3/promo/promoinit.cgi?dirDB=TF_8.3) (Table II). It predicted high-frequency transcription factors 
Table II. Predicted transcription factors of B-cell lymphoma-2-associated transcription factor 1.

\begin{tabular}{lc}
$\begin{array}{l}\text { Name of } \\
\text { transcription } \\
\text { factor }\end{array}$ & $\begin{array}{c}\text { Predicted number } \\
\text { of binding } \\
\text { sites }\end{array}$ \\
\hline C/EBP $\beta$ & 37 \\
GR- $\beta$ & 26 \\
YY1 & 14 \\
TFIID & 9 \\
GR- $\alpha$ & 7 \\
TFII-I & 4 \\
FOXP3 & 3 \\
HNF-3 $\alpha$ & 2 \\
GR & 2 \\
NF-AT2 & 1 \\
AP-2 $\alpha$ A & 1 \\
HNF-1A & 1 \\
NF-AT1 & 1 \\
HOXD9 & 1 \\
HOXD10 & 1 \\
C/EBP $\alpha$ & 1 \\
c-Jun & 1 \\
STAT4 & 1 \\
PR B & 1 \\
PR A & 1 \\
\hline
\end{tabular}

may participate in the regulation of BCLAF1 expression by activating or inhibiting the transcription of BCLAF1.

In summary, multiple studies have revealed that the expression and function of BCLAF1 is regulated at different levels and in different biological processes $(8,13,15,20,22,24,30,34-36,38)$. Compared to the transcriptional and translational levels, studies on the post-translational modification of BCLAF1 are limited, such as ubiquitination, which has not yet been reported. In addition, the high-frequency transcription factors predicted by the PROMO database, that can regulate the transcription of BCLAF1, require further verification, such as from dual-luciferase or chromatin immunoprecipitation assays.

\section{Downstream targets regulated by BCLAF1}

BCLAF1 has numerous downstream targets and participates in a series of biological processes. Previous research has shown that BCLAF1 positively regulated TP53 expression by interacting with the CPE-TP53 during DNA damage (9). Analogously, another study showed that high doses of ionizing radiation (IR) triggered rapid phosphorylation of BCLAF1 and enhanced the binding of BCLAF1 to CPE-TP53 (Fig. 1B-a) (7). Furthermore, Rénert et al (32) confirmed that BCLAF1 played an important role in ceramide-mediated apoptosis of human HCT-116 colon carcinoma cells. BCLAF1 not only promoted the transcription of apoptosis-related proteins, such as TP53 and BAX, but also inhibited the transcription of the TP53 inhibitor, MDM2 (Fig. 1B-b) (32). All these results indicated that BCLAF1 participated in apoptosis and DNA damage in a TP53-dependent manner.

Hypoxia-inducible factors (HIFs) serve an indispensable role in the response of cancer cells to hypoxic stress, maintaining cell survival and growth by activating gene transcription containing hypoxia-responsive elements $(53,54)$. In hypoxic conditions, BCLAF1 binds the promoter region of HIF-1 $\alpha$ via the bZIP domain, directly activating its transcription and promoting HIF- $1 \alpha$-mediated angiogenesis in HCC (Fig. 1A and B-e) (30). In addition, BCLAF1 could reduce HIF-1 $\alpha$ ubiquitination and subsequent degradation by the binding of the MYB domain to the helix-loop-helix domain of HIF-1 $\alpha$ (Fig. 1A) (55). In addition, studies have shown that lncRNA NEAT1 promotes the resistance of cancer cells to astib, bortezomib, paclitaxel, doxorubicin and cisplatin in ovarian cancer, leukemia and gastric cancer cell lines (56-58). Mou et al (31) revealed that BCLAF1 interacted with the promoter region of IncRNA NEAT1 and activated its transcription, thereby promoting the proliferation, invasion and resistance of HCC cells to 5-fluorouracil (5-Fu) (Fig. 1B-e). Furthermore, BCLAF1 has also been reported to be involved in post-transcriptional regulation. Zhou et al (39) demonstrated that BCLAF1 was a key post-slicing regulator of $c-M y c$ mRNA stability and it could protect mature $c$-Myc mRNA from degradation by the RS domain in $\mathrm{HCC}$; however, the specific regulatory mechanism involved is unclear (Fig. 1A and B-e).

\section{BCLAF1, HIF-1 $\alpha$ and NF-אB in cancer}

BCLAF1 and $N F-\kappa B$ in cancer. NF- $\mathrm{NB}$ is an important transcription factor that regulates a variety of pathophysiological processes involved in cell survival and death (59-62), particularly by inhibiting apoptosis in the process of carcinogenesis and cancer progression, thereby promoting tumor growth $(63,64)$. However, BCLAF1 acts an inducer of apoptosis $(1,7,9,23,32,35,38)$ and has an opposing effect to NF- $\kappa$ B in the regulation of apoptosis. A study showed that following stimulation by $\mathrm{T}$ cell receptor and CD28 signals, Rel-A could be significantly induced to bind to the BCLAF1 promoter and promote its transcription, leading to the activation and maturation of immature $\mathrm{CD}^{+}{ }^{+} \mathrm{T}$ cells (24). In another study, BCLAF1 was found to be directly downstream of $N F-\kappa B$, which was bound to the BCLAF1 promoter and activated transcription of BCLAF1 in DNA damage-induced senescence (8). Li et al (35) demonstrated that NF- $\mathrm{BB}$ inhibited BCLAF1 expression and BCLAF1-mediated apoptosis in DLBCL cells; however, the specific mechanism is not clear (Fig. 1B-h).

Overall, these studies collectively indicated that $\mathrm{NF}-\kappa \mathrm{B}$ is directly upstream of BCLAF1, but the regulatory effect of $\mathrm{NF}-\kappa \mathrm{B}$ on BCLAF1 was observed with different results. NF- $\kappa \mathrm{B}$ could act as a positive regulator to activate the transcription of BCLAF1 and it has also been found that NF- $\mathrm{B}$ could repress the mRNA and protein expression level of BCLAF1. Given the insufficient research on the interaction between $\mathrm{NF}-\kappa \mathrm{B}$ and BCLAF1 in cancer, further investigation is required.

BCLAF1 and HIF-1 $\alpha$ in cancer. HIF-1 $\alpha$ is a well-defined hypoxia response factor, which can activate a variety of pathways regulating angiogenesis, cell metabolism, proliferation and drug resistance $(54,65)$. Wen et al (30) reported that the 
mRNA and protein expression levels of HIF-1 $\alpha$ and BCLAF1 in tumor tissues were significantly higher compared with that in the adjacent normal tissues and were positively correlated. Furthermore, in the nude mouse xenograft tumor model, it was also confirmed that BCLAF1 significantly promoted HCC angiogenesis and tumor growth (30). Mechanistic studies have shown that BCLAF1 promotes angiogenesis by activating the transcription of HIF-1 $\alpha$, which in turn promotes the proliferation, angiogenesis, and metastasis of HCC cells (Fig. 1B-e) (30). Notably, HIF-1 $\alpha$ could in turn activate the transcription of BCLAF1 and form a closed loop with BCLAF1 (30). In another study, BCLAF1 also maintained HIF-1 $\alpha$ activity by binding to HIF-1 $\alpha$ and protecting HIF-1 $\alpha$ from degradation under long-term hypoxia, and BCLAF1 may enhance the stability of HIF-1 $\alpha$ to promote tumor progression (55). In addition, Zhang et al (42) demonstrated that the ginsenoside, compound K (CK; a ginsenoside diol type saponins, which has a variety of pharmacological activities, including anti-inflammatory, hepatoprotective and antitumor effects) (66), inhibited the HIF-1 $\alpha$-mediated glycolysis pathway by downregulating the protein expression level of BCLAF1, thereby inhibiting the proliferation of liver cancer cells.

In summary, several studies have confirmed that BCLAF1 upregulates the expression level of HIF-1 $\alpha$; therefore, participates in different biological processes, such as cell proliferation, angiogenesis and cell metabolism $(30,42,55)$. In particular, in HCC, which is characterized by a hypoxic microenvironment, HIF-1 $\alpha$-mediated angiogenesis and anaerobic glycolysis notably promoted the occurrence and development of HCC. Therefore, targeting the BCLAF1-HIF-1 $\alpha$ pathway may represent a preclinical treatment strategy for HCC.

\section{Physiological function of BCLAF1}

BCLAF1 is involved in mediating numerous physiological processes, such as DDR $(3,4,7,8,9)$, pre-mRNA splicing and processing (2-6), apoptosis $(1,7,9,12,23,32,35,37,38)$, cell cycle $(1,7)$, lung development (10), T-cell activation $(12,24,25)$, and muscle cell proliferation and differentiation (17-20). The current knowledge arises from physiological evidence obtained from mouse and cell models, pathological evidence from human tumor cell lines and disease cell models, and biochemical evidence from in vitro studies of substrates that can interact with BCLAF1 and participate in several physiological processes (Table III). Loss of functional Emerin, a nuclear membrane protein, causes X-linked recessive Emery-Dreifuss muscular dystrophy (EDMD) (17). Haraguchi et al (18) found that Emerin could bind to BCLAF1 and co-locate to the nuclear membrane, and participate in the regulation of apoptosis, and the proliferation and differentiation of muscle cells (Fig. 1B-j). In addition, the loss of binding of Emerin to BCLAF1 may be associated with muscle atrophy in EDMD (Table III and Fig. 1B-j) (18). Furthermore, Wang et al (20) demonstrated that circular RNA Zfp609 (circZfp609) regulated muscle cell differentiation by sponging miR-194-5p. Specifically, circZfp609 could sponge miR-194-5p to sequester its inhibition on BCLAF1 and repress myogenic differentiation; however, the specific mechanism is unclear. Notably, numerous studies have shown that BCLAF1 is a key apoptosis regulator; however, its specific role is still controversial.
At present, most reports indicate that BCLAF1 promotes apoptosis via various mechanisms, such as antagonizing the anti-apoptosis effect of Bcl-2 (1) and upregulating the expression of apoptosis-related proteins, such as TP53, BAX and caspase-3 (Fig. 1B-a) $(7,9,23,32)$. However, in one study, after a variety of chemical apoptosis inducers (such as anisomycin, etoposide and staurosporine) and $\gamma$-irradiation were used, BCLAF1-deficient T cells and B cells did not show notable apoptotic disorders, suggesting that BCLAF1 was not necessary for apoptosis (12). In another study, BCLAF1-mediated autophagy of HCC cells could enhance cell proliferation and prevent cell apoptosis under stress conditions (37). Similar to tumorigenesis, the regulation of BCLAF1 on apoptosis may be dependent on cell type and cell context; however, further investigation is required.

\section{Roles of BCLAF1 in human cancer}

BCLAF1 is a nuclear protein, which was first found to interact with Bcl-2 and promote apoptosis (1). Furthermore, BCLAF1 has been found to induce apoptosis by activating the transcription of TP53 (9). Subsequently, BCLAF1 was identified as a potential tumor suppressor by promoting the apoptosis of colon adenocarcinoma cells and bladder cancer (BC) cells $(32,43)$. Collectively, another three studies also confirmed that BCLAF1 acted as a tumor suppressor in lung cancer (LC), multiple myeloma (MM) and DLBCL $(7,21,35)$. However, recently, BCLAF1 has become a hot topic due to its carcinogenic characteristics in certain types of human cancer, including colorectal cancer (CRC) (34), BC (22,36), AML (38), LC (40), HCC $(30,31,37,39,42)$ and gastric cancer (11). These differences indicated that the specific role of BCLAF1 in tumor progression may depend on the cellular context and type of cancer (Table IV).

$B C$. Human $\mathrm{BC}$ is one of the most common malignant tumors and was the second leading cause of mortality in patients with cancer of the urogenital tract worldwide in $2018(67,68)$. Yoshitomi et al (43) found that miR-517a, as a tumor suppressor, was downregulated in BC cells, and overexpression of miR-517a could significantly inhibit cell proliferation and induce apoptosis. Furthermore, following transfection of miR-517a mimics in BC cells, oligonucleotide array analysis identified significant upregulation of BCLAF1; however, the mechanism involved is not clear (43). It is well-known that miRNAs can inhibit transcription by binding to the 3'-UTR of a target molecule (52). For example, miR-K5 (15) and miR-UL112-1 (13) both inhibited the translation of BCLAF1 by binding to its 3'-UTR (Fig. 1B-d). Therefore, these results suggested that miR-517a may inhibit cell proliferation and promote cell apoptosis by indirectly upregulating the expression of BCLAF1 in the BC, and that BCLAF1 acted as a potential tumor suppressor in $\mathrm{BC}$.

However, certain subsequent studies have reported different conclusions. In one study, compared with that in para-carcinoma tissues, the relative expression level of BCLAF1 was significantly increased ( $\sim 1.82$ times) in BC samples $(\mathrm{P}=0.002)(36)$. Furthermore, the knockdown of $B C L A F 1$ inhibited the proliferation of $\mathrm{BC}$ cells and promoted the apoptosis of $\mathrm{BC}$ cells (36). In addition, in a mouse 


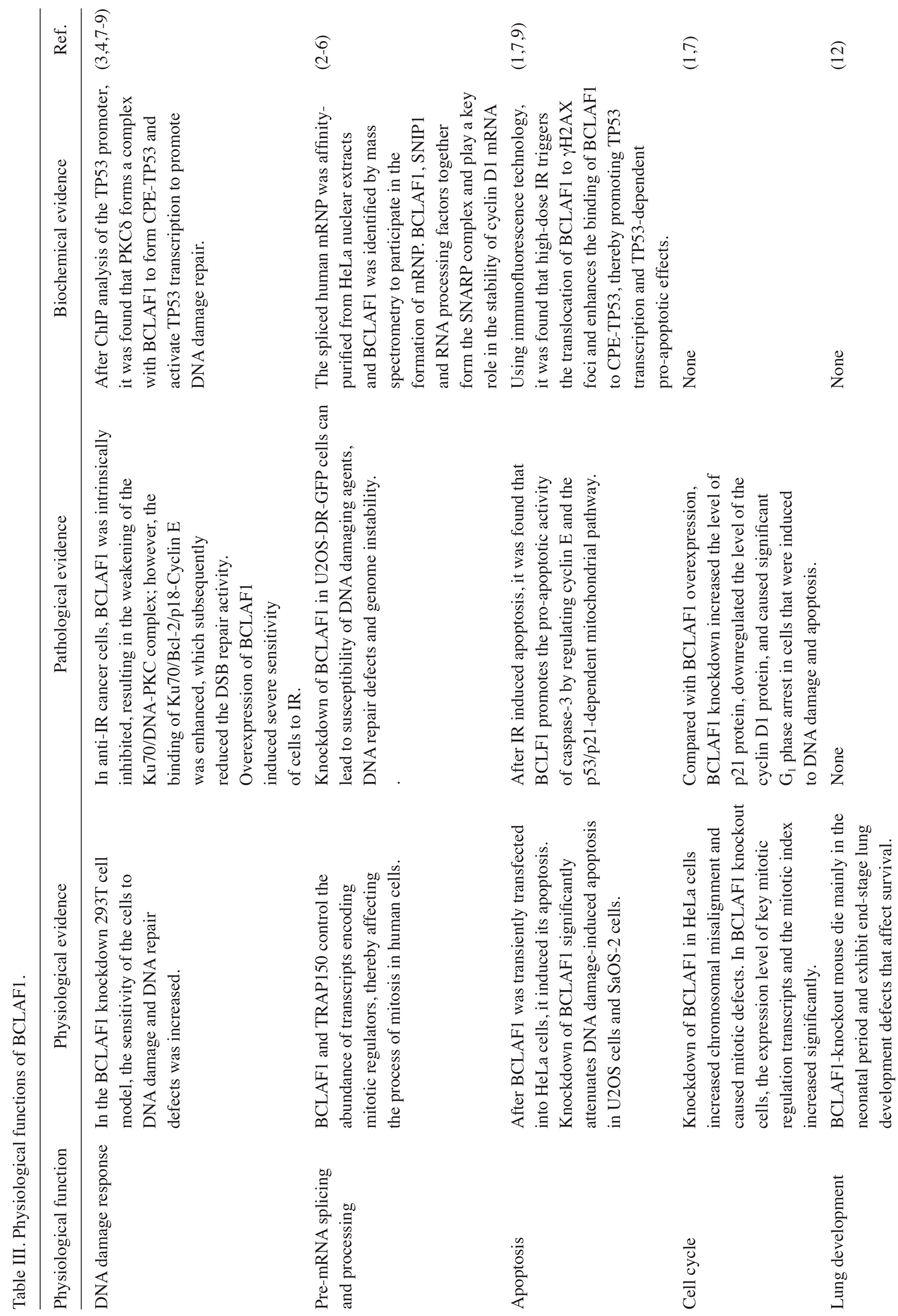




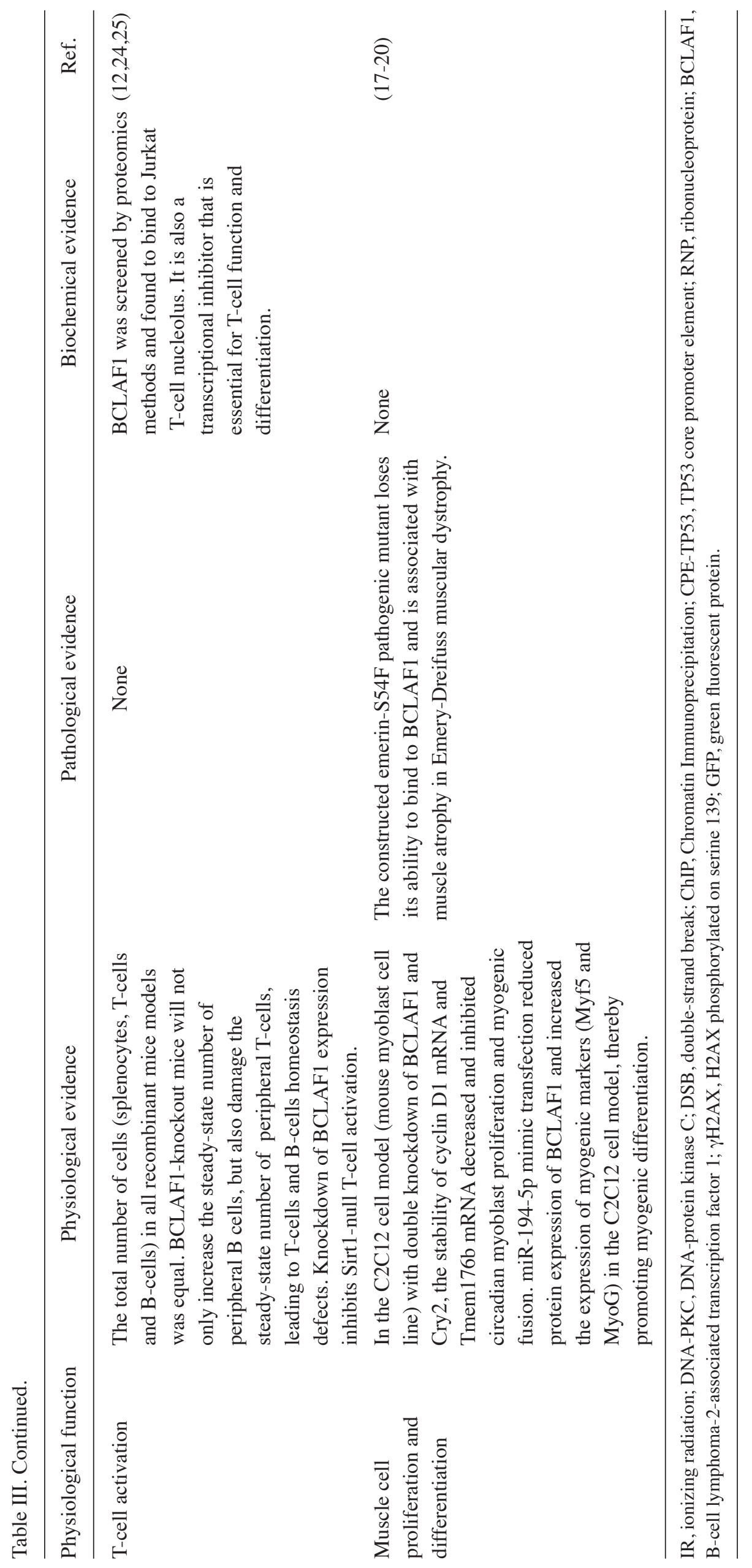




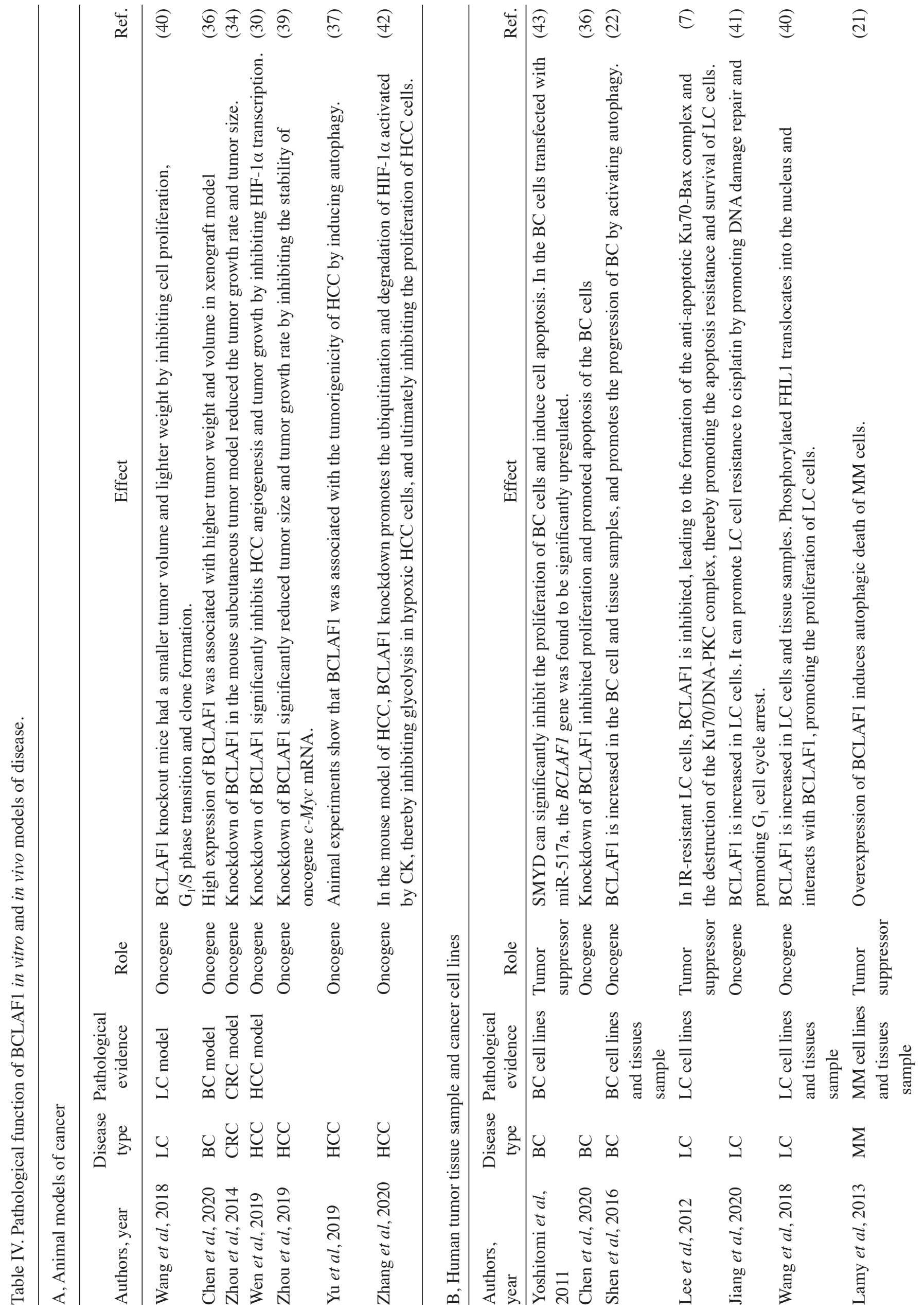




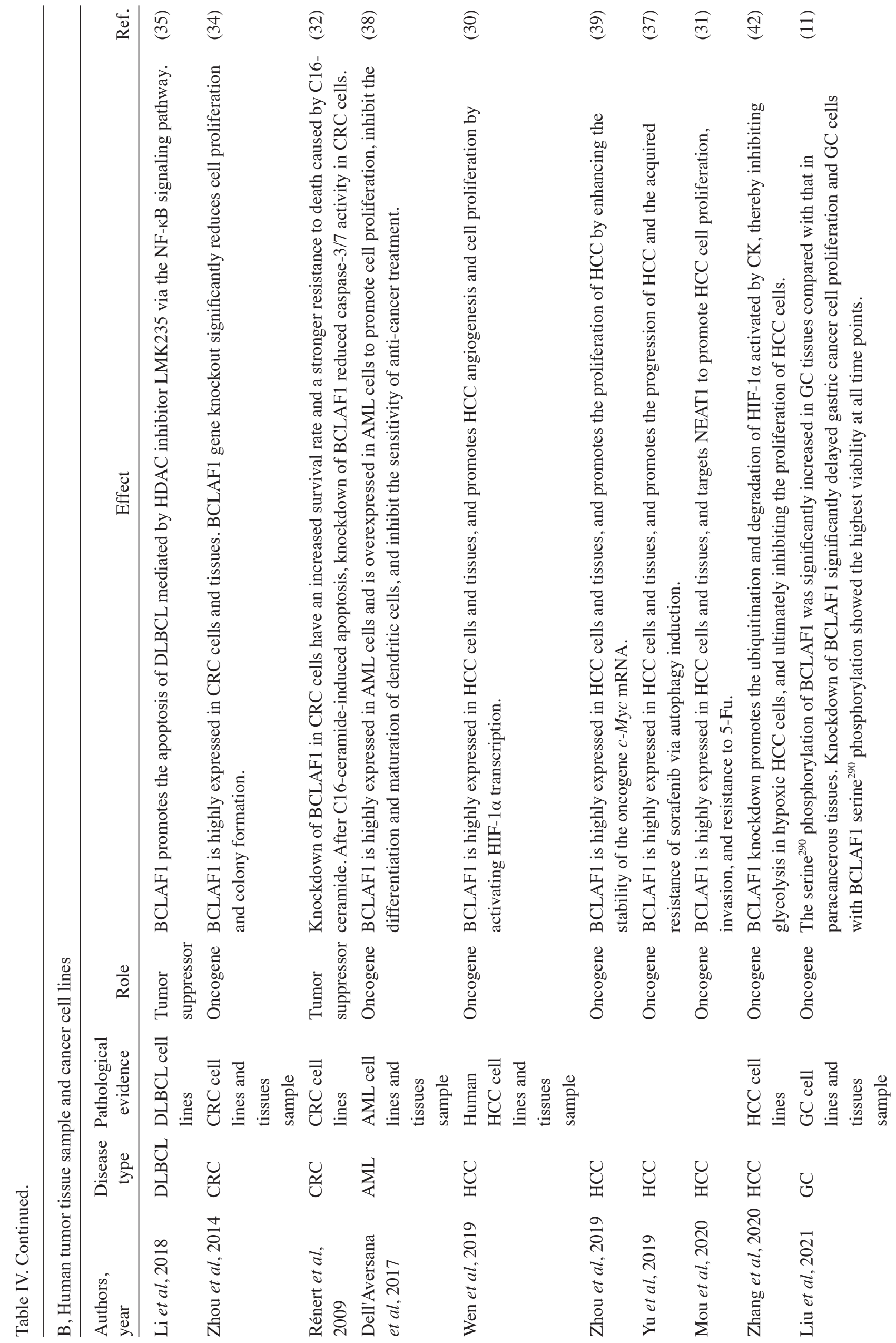




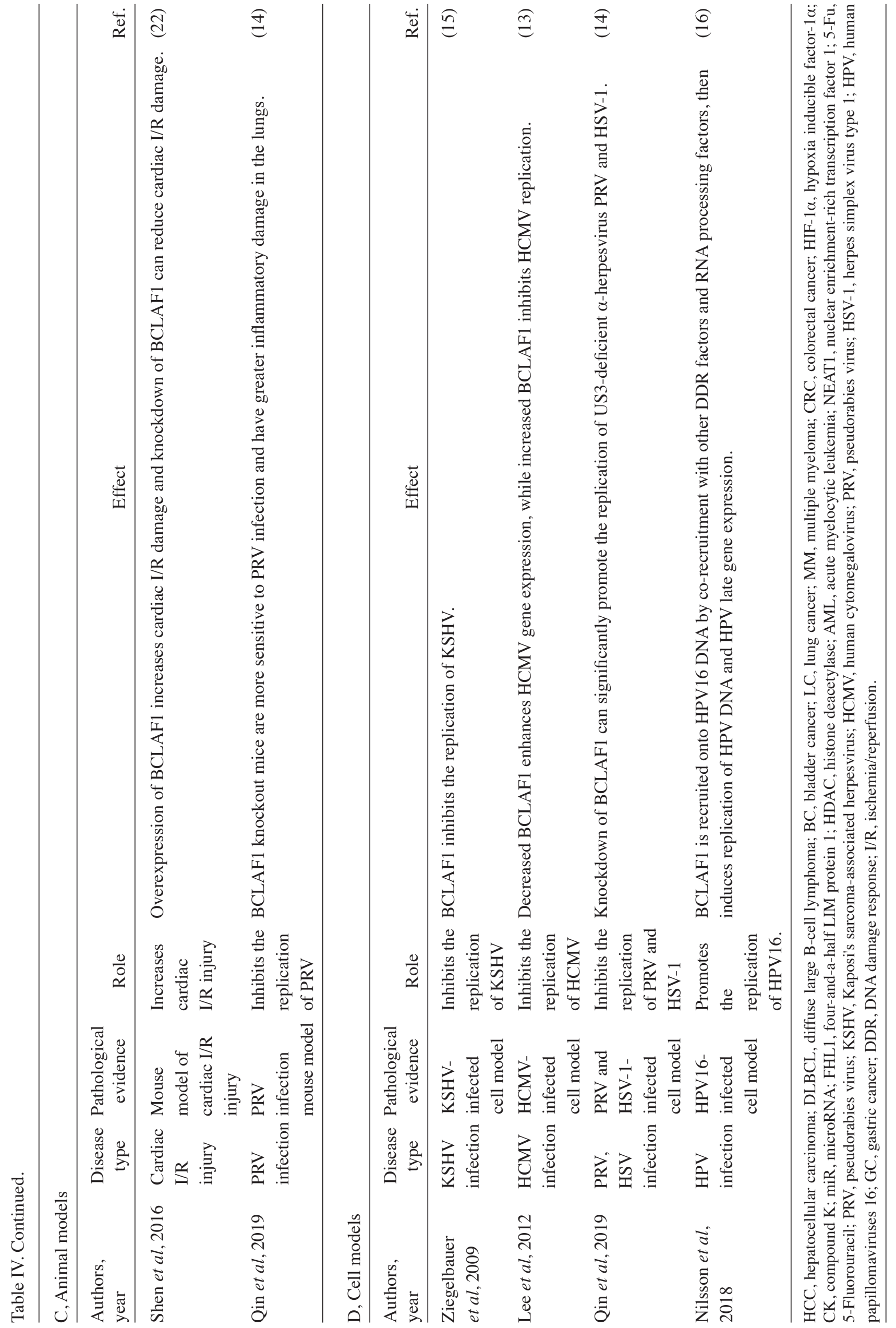


xenograft tumor model, BCLAF1facilitated the tumorigenicity of BC (36). Mechanistically, miR-194-5p bound to the 3'-UTR of BCLAF1 and inhibited the translation of BCLAF1. In addition, IncRNA PVT1 acted as a miRNA sponge to actively promote the expression level of BCLAF1 by sponging miR-194-5p and subsequently increased the malignant phenotype of BC (Fig. 1B-g) (36). Epigenetic studies have shown that the dysfunction of histone methylation and its modifications may serve an important role in tumorigenesis and development (69,70). SMYD3 is a histone methyltransferase, which has been reported to be involved in tumorigenesis, cancer cell proliferation, invasion and migration (71,72). Shen et al (22) discovered that compared with that in adjacent normal controls, SMYD3 and BCLAF1 mRNA and protein expression levels were significantly upregulated in 77\% (17/22) of BC tissues. Mechanistic research showed that the overexpression of SMYD3 activated the transcription of BCLAF1 by increasing the methylation of histone H3K4 and SMYD3 promoted the progression of $\mathrm{BC}$ by targeting BCLAF1 to activate autophagy (Fig. 1B-g) (22). Notably, there have been reports that BCLAF1 was a strong autophagy inducer by replacing bcline-1 in Bcl-2 $(21,73)$. As the heterogeneity of tumors is considered to be a sign of BC (74), it could be hypothesized that the differential expression and different roles of BCLAF1 in BC may be associated with the significant heterogeneity of $\mathrm{BC}$.

$L C$. LC was the leading cause of cancer worldwide and cancer-associated mortality in 2020 , with an $\sim 1.8$ million (18\%) deaths (75). In one study, DNA-PKC was specifically activated and phosphorylated BCLAF1 at tyrosine ${ }^{150}$ and serine ${ }^{151}$ in IR-reactive cells (293T, MRC-5 and WI-38 cell lines) under a high dose of IR, which resulted in BCLAF1 relocating to the nuclear envelope, then binding with $\gamma \mathrm{H} 2 \mathrm{AX}$ foci, which in turn stabilized the Ku70/DNA-PKC complex to facilitate the non-homologous end-joining (NHEJ) pathway of double-strand break (DSB) repair (Fig. 1B-a) (7). Ku70 is a DNA repair factor in the cell nucleus, forming a heterodimer with Ku80 via the central domain to bind double-stranded (ds) DNA, which is essential for the DSB repair of the NHEJ pathway of dsDNA (76-78). At the same time, BCLAF1 prevents p21-dependent $G_{1}$ cell cycle arrest, downregulation of cyclin E protein expression level, and inhibition of the pro-apoptotic factors, caspase- 3 and BAX, by repressing the p21 protein expression level, thereby promoting cell apoptosis and cell cycle progression (Fig. 1B-a) (7). However, BCLAF1 was inhibited in LC cells with natural radioresistance. On the one hand, the formation of the Ku70/DNA-PKC complex decreased and DNA repair was impaired; on the other hand, p21-dependent cell cycle arrest was increased, and the caspase-dependent apoptosis pathway, mediated by Ku70, was inhibited, which eventually resulted in carcinogenesis (Fig. 1B-a) (7). Overall, BCLAF1 served as a tumor suppressor in LC by promoting DNA repair, apoptosis and inhibiting cell cycle arrest.

However, subsequent studies have discovered that BCLAF1 may serve a different role in LC. Four-and-a-half LIM protein 1 (FHL1) was identified in early studies as a tumor suppressor factor and its expression level was significantly decreased in a variety of cancers, including LC (79), HCC (80) and breast cancer (81). Conversely, a previous study found that the role of FHL1 in cancer progression could be to promote tumorigenesis (82). In addition, Wang et al (40) confirmed this conclusion, as they found that phosphorylation of FHL1 promoted LC cell proliferation. Specifically, phosphorylated FHL1 translocated into the nucleus and interacted with BCLAF1, then promoted the proliferation of the H1299 non-small cell lung cancer (NSCLC) cell line (Fig. 1B-a) (40). Furthermore, in a nude mouse xenograft tumor model, BCLAF1 knockout cells exhibited a smaller tumor volume and weight (40). These results indicated that BCLAF1 could be a potential tumorigenic factor in LC. Furthermore, another group revealed that the protein and mRNA expression levels of $B C L A F 1$ were higher in the cisplatin-resistant A549 NSCLC cell line (41). Cisplatin is a widely used small molecule chemotherapeutic drug (83), it can bind and cross-link with DNA, thereby destroying DNA function, repressing mitosis and subsequently inducing cell apoptosis $(84,85)$. Further research found that BCLAF1 may induce cisplatin resistance in two ways; i) BCLAF1 could increase ubiquitin-specific peptidase 22 (USP22) mRNA expression to promote DNA repair, thereby inducing cisplatin resistance (41). It has been previously reported that USP22 overexpression could promote cisplatin resistance in the A549 cell line, then regulated Ku70/BAX-dependent apoptosis and $\gamma \mathrm{H} 2 \mathrm{AX}$-mediated DNA damage repair (86); and ii) BCLAF1 induced $\mathrm{G}_{1}$ cell cycle arrest by increasing the p21 protein expression level and decreasing the cyclin D1 protein expression level, which resulted in cisplatin resistance (41). These studies indicated that BCLAF1 could promote LC cell proliferation and resistance to cisplatin by targeting FHL1, promoting DNA damage repair and $\mathrm{G}_{1}$ cell cycle arrest. However, the exact role and mechanism of action of BCLAF1 in LC requires further investigation.

CRC. CRC was the second most common cause of cancer-associated mortality worldwide in 2018 , with a high incidence rate in Westernized countries, while the incidence rate is currently on the rise in Asian countries (87). There are a few studies on the role of BCLAF1 in CRC. In 2009, Rénert et al (32) first reported the pro-apoptotic effect of BCLAF1 in colon cancer cell lines. It was found that C16-ceramide, the core molecule involved in sphingomyelin metabolism relied on BCLAF1 to promote the apoptosis of colon cancer cells (32). Furthermore a mechanistic study reported that BCLAF1 promoted the apoptosis of colon cancer cells by regulating apoptosis-related proteins (activating the transcription of TP53 and BAX, and inhibiting the transcription of MDM2) (Fig. 1B-b) (32). Notably, in the present review the survival prediction analysis of BCLAF1 in patients with CRC using the GEPIA2 database, showed that high mRNA expression level of BCLAF1 was associated with a favorable overall survival rate in 290 patients, while low mRNA expression level was associated with poor overall survival in 290 patients $(\mathrm{P}=0.026)$ (Fig. 3A). Collectively, these results indicate that BCLAF1 could be a potential tumor suppressor in CRC.

However, another group strongly challenged this conclusion. Zhou et al (34) discovered that the expression of the $\mathrm{L}$ isoform of BCLAF1 was increased in CRC cell lines, suggesting that the $\mathrm{L}$ isoform may serve a key role in colorectal tumorigenesis (34). Furthermore, the overexpression of the 
$\mathrm{L}$ isoform promoted the proliferation and colony formation of CRC cells (34). In addition, the splicing factor, SRSF10 was found to be a direct upstream regulatory molecule of BCLAF1 and participated in the production of the $\mathrm{L}$ isoform via the inclusion of exon $5 \mathrm{a}$, which promoted the tumorigenesis of CRC (Fig. 1B-b) (34). In addition, the knockdown of the $\mathrm{L}$ isoform in a mouse subcutaneous tumor model reduced the tumor growth rate and tumor size, which also confirmed the role of the $\mathrm{L}$ isoform in promoting tumorigenesis and development of CRC (34). Overall, these results indicated that the role of BCLAF1 in CRC could be contradictory, possibly as either a tumor suppressor or tumor-promoting factor. Therefore, an in-depth investigation is required to determine the role of BCLAF1 in CRC.

$H C C$. HCC was the fourth leading cause of cancer-related mortality worldwide and the leading cause of death among patients with cirrhosis in 2019 (88). However, studies focusing on the role of BCLAF1 in the tumorigenesis of HCC have not been reported until recently. As aforementioned, multiple studies have shown that BCLAF1 was associated with the regulation of angiogenesis, cell proliferation and drug resistance in HCC under hypoxic conditions by activating the transcription of HIF-1 $\alpha$ (Fig. 1B-e) $(30,42,55)$. Furthermore, Zhou et al (39) found that, compared with that in adjacent tissues and normal hepatocytes, the BCLAF1 protein expression level in HCC tissues and cell lines was significantly increased and in a nude mouse xenograft tumor model, knockdown of BCLAF1 significantly reduced tumor size and tumor growth rate. Mechanistically, Hsp $90 \alpha$ interacted with BCLAF1 and prevented its subsequent degradation via the proteasome pathway (Fig. 1B-e) (39). Furthermore, BCLAF1 protected the mature mRNA of the oncogene $c-M y c$ from degradation via its RS domain, thereby promoting the occurrence and progression of HCC (Fig. 1A and B-e) (39). In addition, another group also confirmed that BCLAF1 was highly expressed in HCC specimens compared with that in adjacent normal tissues, and higher BCLAF1 protein expression levels were associated with higher TNM stage, poorer differentiation and a less favorable prognosis in patients with HCC (6). In addition, BCLAF1 induced autophagy in response to starvation of the HCC cells, and BCLAF1 might increase cell proliferation and prevent cell apoptosis under stress conditions by inducing autophagy (6). Animal experiments also showed that BCLAF1 facilitated the tumorigenicity of HCC cells in vivo (37). In addition, the high BCLAF1 protein expression levels may lead to sorafenib resistance in patients with $\mathrm{HCC}$ (37). Consistent with the two aforementioned studies, Mou et al (31) also verified that BCLAF1 was highly expressed in HCC cells and tissues. Furthermore, additional research also found that BCLAF1 could bind to the lncRNA NEAT1 promoter and activate its transcription, thereby promoting cell proliferation, invasion and resistance to 5-Fu (Fig. 1B-e) (31). A recent study found that BCLAF1 might play a regulatory role in $\mathrm{HCC}$ by mediating the glycolytic pathway: Zhang et al (42) discovered that knockdown of BCLAF1 could enhance the ability of ginsenoside $\mathrm{CK}$ to activate HIF-1 $\alpha$ ubiquitination and inhibit the glycolysis pathway, mediated by HIF-1 $\alpha$, leading to inhibition of HCC cell proliferation. In addition, in a mouse model of $\mathrm{HCC}$, induced by diethylnitrosamine, after the administration of CK, both the volume and the glucose uptake ability of the tumor was reduced (42). Multiple studies have also confirmed that enhanced glycolysis was associated with the tumorigenesis and progression of tumors $(89,90)$. Collectively, these studies showed that BCLAF1 was a tumor-promotor in HCC, promoting the proliferation, migration and invasion, angiogenesis and drug resistance of HCC via different mechanisms.

MM. MM is a clonal malignant tumor caused by the uncontrolled proliferation of immunoglobulin-secreting plasma cells in the bone marrow and it accounts for $10 \%$ of all hematological malignancies (91). Lamy et al (21) used short hairpin RNAs in a retroviral library to identify essential pathways in MM and to determine potential therapeutic targets in MM. It was found that caspase-10 was essential for MM viability and did not induce apoptosis, but instead blocked autophagy-dependent cell death pathways in MM (21). Caspase-10 has been reported to be involved in the formation of death-inducing signaling complex (DISC) and induced the proteolysis of their downstream targets, which resulted in the initiation of extrinsic apoptosis (92). However, it has been reported that caspase-10 can change the apoptotic cell death response following the formation of DISC to activate $\mathrm{NF}-\kappa \mathrm{B}$ and cell survival (93). Furthermore, the gene expression analysis following caspase-10 knockdown revealed that $B C L A F 1$ was one of the upregulated genes. In particular, the level of BCLAF1 protein induction was greater than that for the mRNA expression level (21). This suggests that BCLAF1 may be a substrate of caspase-10. Further in vitro experiments indicated that caspase- 10 protected MM cells from autophagic death, induced by BCLAF1 from the cleavage of aspartic acid at position 452 in BCLAF1 (Fig. 1A and B-c) (21). As aforementioned, BCLAF1 is a strong autophagy inducer by replacing beclin-1 in Bcl-2 (Fig. 1B-c) $(21,72)$. These results verified that the interaction between BCLAF1 and Bcl-2 increased following caspase-10 inhibition, leading to the dissociation of beclin-1 from Bcl-2, thereby initiating autophagy. Overall, BCLAF1 could act as a tumor suppressor by inducing the autophagic death of MM cells.

$D L B C L$. DLBCL is a biologically and clinically heterogeneous B-cell tumor. Its morphology is characterized by large lymphocytes and B-cell markers proliferating rapidly and in a diffuse pattern (94). HDACi are a new type of drug for the treatment of hematological malignancies, which can increase histone acetylation, induce apoptosis and differentiation, and inhibit the proliferation of tumor cells (95-97). LMK-235 is a specific inhibitor of HDAC4 and HDAC5 (98). A study has shown that after treating DLBCL cells with LMK-235, both the mRNA and protein expression level of BCLAF1 and the rate of apoptosis increased (35). Similar results were observed after the HDAC4 gene was knocked down (35). In addition, LMK-235 increased the BCLAF1 protein expression level by inhibiting the NF- $\kappa$ B pathway (35). Furthermore, both LMK-235 and small interfering (si)RNA-HDAC4 inhibited the activation of $\mathrm{NF}-\kappa \mathrm{B}$ and increased the BCLAF1 protein expression level, and the NF- $\kappa$ B inhibitor, Bay11-7082 increased the BCLAF1 protein expression level (Fig. 1B-h) (35).

In summary, BCLAF1 may represent a potential tumor suppressor in DLBCL, and LMK-235 increases the BCLAF1 
protein expression level by inhibiting the activation of NF- $\mathrm{NB}$, then promoting the apoptosis of DLBCL cells. Notably, previous studies found that $\mathrm{NF}-\kappa \mathrm{B}$ inhibited the $B C L A F 1$ mRNA expression level in different cellular processes. Shao et al (8) showed that BCLAF1 was a direct downstream target of $\mathrm{NF}-\kappa \mathrm{B}$, which bound to the BCLAF1 promoter and activated its transcription during therapeutic drug doxorubicin-induced senescence. Similarly, another study showed that in the regulation of BCLAF1 histone acetylation, Rel-A bound to the BCLAF1 promoter and activated its transcription (24). A recent study suggested that BCLAF1 might play a pro-apoptotic effect in DLBCL through negative regulation by NF- $\mathrm{KB}$ (Fig. 1B-h) (35); however, the specific regulatory mechanism is still unclear. As it has been previously reported that $\mathrm{NF}-\kappa \mathrm{B}$ could activate the transcription of BCLAF1, further studies are required to verify whether BCLAF1 could also be involved in the development of DLBCL via the transcriptional regulation of $\mathrm{NF}-\kappa \mathrm{B}$.

AML. AML is a type of cancer derived from the myeloid lineage of blood cells. It is characterized by the excessive production of leukemic mother cells, but the survival rate is still low due to the high recurrence rate (99). BCLAF1 mRNA and protein expression level was found to be highly expressed in AML cells compared with that in normal CD34+ cells, while the opposite effect was observed with respect to the level of miR-194-5p (38). In addition, lower BCLAF1 mRNA and protein expression levels (and higher miR-194-5p expression levels) were associated with a favorable prognosis based on the 5-year survival rate (38). It was further found that miR-194-5p bound to the 3'-UTR of BCLAF1 and inhibited the translation of BCLAF1 in AML (Fig. 1B-c) (38). Furthermore, overexpression of miR-194-5p and the accompanying decrease in the expression of BCLAF1 resulted in $\mathrm{G}_{1}$ cell cycle arrest and caspase 9-dependent activation of apoptosis in AML cells (38). In addition, BCLAF1 knockdown cells were more sensitive to the AML treatment drug, suberoylanilide hydroxamic acid (a HDACi), and the proliferation and number of AML colonies formed were notably reduced (38). All these results showed that BCLAF1 might be a potential tumor-promoting factor in AML.

\section{BCLAF1 and RT}

RT is an important treatment modality for localized tumors (100). RT produces DNA DSBs using high-energy IR, which induces cell cycle arrest, senescence and various tumor cell death modes, including apoptosis, autophagy, necrosis and mitotic catastrophes (101). After IR-induced cellular DNA damage, H2AX responds to DSBs by phosphorylating serine $^{139}(\gamma \mathrm{h} 2 \mathrm{AX})$ and subsequently recruits various proteins, that are associated with apoptosis and repair of DNA damage, such as BRCA1 and RAD51 (102). A number of studies have associated BCLAF1 with DDR. Liu et al (9) first reported that BCLAF1 promoted the transcription of TP53 by forming a complex with $\mathrm{PKC} \delta$ in response to DNA damage. Lee et al (7) found that the complex formed by BCLAF1 and $\gamma \mathrm{H} 2 \mathrm{AX}$ was co-localized to the damaged DNA and could stabilize the Ku70/DNA-PKC complex to facilitate the NHEJ pathway of DSB repair (Fig. 1B-a). Similarly, in the latest research, IR induced phosphorylation of serine ${ }^{290}$ in BCLAF1 and the co-localization of BCLAF1 with $\gamma \mathrm{H} 2 \mathrm{AX}$, which promoted DDR and radiotherapy resistance of gastric cancer cells (Fig. 1B-i) (11). In addition, Savage et al (3) discovered that BCLAF1 was identified in the protein interacting with BRCA1, which mediated the formation of the BRCA1-mRNA splice complex after DNA damage, and knockdown of BCLAF1 increased cell sensitivity to IR. Similar results were found in a comparable study (4). Notably, a recent report showed that after IR induction, BCLAF1 increased the mRNA expression level of programmed cell death ligand 1 (PD-L1) via the DNA DSB repair pathway, thereby increasing the resistance of the cells to IR (10). It is well-known that PD-L1 is a negative regulator of the immune response and blocking antibodies targeting PD-L1 can reactivate immune surveillance $(103,104)$. In addition, mounting evidence has revealed that the synergistic combination of radiotherapy and immunotherapy could provide significant therapeutic effects in NSCLC $(105,106)$. Therefore, it would be important to further investigate the role of BCLAF1 in the combined treatment of tumors with radiotherapy and chemotherapy.

Taken together, numerous studies have shown that BCLAF1 is a DDR-associated protein and serves an important role in DDR $(3,4,7,9,10,11)$. In addition, for normal cells, DDR is a key pathway for maintaining genomic stability and preventing oncogenic transformation (100). Whereas, for tumor cells, high levels of DDR may increase IR-induced DSB, promote tumor cell resistance to RT and eventually lead to treatment failure $(3,4,10,11)$. Therefore, targeting BCLAF1 may be an effective therapeutic strategy against radioresistance in the future.

\section{Roles of BCLAF1 in virus replication}

In addition to participation in the occurrence and development of several types of malignant tumor, studies have also found that BCLAF1 serves an important role in virus replication. Ziegelbauer et al (15) discovered, for the first time, that BCLAF1 had a negative regulatory role in the replication of KSHV. Further analysis showed that BCLAF1 was the target of KSHV-encoded miR-K5, by binding to the 3'-UTR of BCLAF1, thus decreasing the mRNA expression level of BCLAF1 (15). $\mathrm{KSHV}$, as a hemolytic virus, is the etiological agent of some malignant tumors associated with acquired immunodeficiency syndrome, such as Kaposi's sarcoma, variants of multicentric Castleman disease and primary effusion lymphoma (107-111). Furthermore, another study demonstrated that decreased BCLAF1 protein expression level enhanced HCMV gene expression, while increased BCLAF1 protein expression level inhibited virus replication (13). Further analysis found that the proteasome degradation of BCLAF1 was induced by releasing viral particle proteins in the early stage after HCMV infection, such as pp71 and UL35 proteins (Fig. 1B-d) (13). In the later stage of HCMV infection, the miR-UL112-1 encoded by HCMV, bound to the 3'-UTR of BCLAF1 and inhibited its translation (13). HCMV is a widespread $\beta$-herpes virus that can cause diseases in individuals with immature or impaired immune systems (112), such as atherosclerosis, vascular disease and immune aging as well as increase the risk in developing different types of tumor $(113,114)$. Furthermore, a recent 
study indicated that knockdown of BCLAF1 could significantly promote the replication of US3-deficient $\alpha$-herpesvirus pseudorabies virus (PRV) and herpes simplex virus type 1 (HSV-1) (14). Mechanistic analysis found that BCLAF1 could repress viral replication by enhancing type I interferon signaling (14). Conversely, PRV induced the degradation of BCLAF1 in host cells during infection via its expressed viral protein, US3 (Fig. 1B-d) (14). Type I interferon response serves an important role in combating viral infections and it is often dysregulated in viral infections (115). In a similar manner to KSHV and HCMV, both PRV and HSV-1 belong to the $\alpha$-herpesvirus subfamily.

In summary, the aforementioned studies have uncovered the role of BCLAF1 in herpes virus defense, and more importantly, that BCLAF1 is also the target of multiple viral components. However, BCLAF1 may play a different role in human papillomaviruses (HPV)16. HPV16 is a small DNA virus that infects keratinocytes of the squamous and mucosal epithelium $(116,117)$. In one study, in cells with induced DNA damage, BCLAF1 was recruited to the HPV16 DNA by co-recruitment with other DDR factors (such as BRCA1 and BARD1) and RNA processing factors (such as U2AF65 and SF3b), then induced replication of HPV DNA and HPV late gene expression (16), indicating the role of BCLAF1 in promoting HPV replication. Taken together, these studies showed that BCLAF1 may serve a contradictory role in viral infections. On the one hand, BCLAF1 represses the replication and infection of some viruses, such as herpes viruses, including KSHV, HCMV, PRV and HSV-1; on the other hand, BCLAF1 promotes the DNA replication and gene expression of HPV16 (Table IV).

\section{Roles of BCLAF1 in cardiac $I / R$ injury}

I/R injury, characterized by oxidative stress, inflammation and organ dysfunction $(118,119)$, is the initial temporary blockage of blood supply to tissues and organs, followed by the recovery of perfused blood supply and accompanying reoxygenation, known as reperfusion injury of tissues and organs. It has recently been reported that overexpression of BCLAF1 increased cardiac I/R injury and increased the infarct size in the heart of a I/R mouse model, and knockdown of BCLAF1 reduced cardiac I/R injury (23). Mechanistically, the translocation of BCLAF1 to the nucleus increased the expression and activity of apoptosis-related proteins, such as TP53, BAX and caspase- 3 induced by I/R injury, then promoted the apoptosis of cardiomyocytes (Fig. 1B-k) (23). In addition, further research has demonstrated that IncCIRBIL was bound to the BCLAF1 protein in the cytoplasm of cardiomyocytes to prevent its translocation to the nucleus, thus repressing cardiac I/R injury (Fig. 1B-k) (23). In summary, BCLAF1 could act as a cardiomyocyte protective factor in cardiac I/R injury and mediate the regulation of IncCIRBIL in cardiac I/R injury (Table IV).

\section{Conclusions}

In conclusion, BCLAF1 has complex physiological and pathological functions, and exerts these biological functions from the regulation of its upstream molecules and the downstream target molecules. On the one hand, BCLAF1, as a downstream molecule, is mostly regulated at the transcriptional and post-transcriptional level. For example, NF- $\kappa \mathrm{B}$ can regulate BCLAF1 transcription by binding to the promoter of BCLAF1 (Fig. 1B-f and h) $(8,24,35)$ and Sirtl can inhibit BCLAF1 transcription by deacetylating the $\mathrm{H} 3 \mathrm{~K} 56$ at the BCLAF1 promoter (Fig. 1B-f) (24). In addition, several studies have found that BCLAF1 was phosphorylated at different sites associated with the repair of DNA damage $(7,31)$. Notably, mass spectrometry found $>30$ phosphorylation sites within BCLAF1 (120); however, the significance and function of these sites have not been reported. Therefore, post-translational modification (such as phosphorylation) of BCLAF1 may be one of the key forms for regulating its function, and further research is required.

On the other hand, BCLAF1 regulates its downstream targets at the transcriptional and post-transcriptional level to participate in numerous physiological and pathological processes. For example, BCLAF1 participates in DDR and apoptosis by activating the transcription of TP53 and BAX (Fig. 1B-a) (7,9). Furthermore, BCLAF1 has been associated with colon cancer and found to activate the transcription of TP53 and BAX, and inhibit MDM2 (Fig. 1B-b) (32). In addition, BCLAF1 was associated with the development of HCC by activating the transcription of HIF-1 $\alpha$ and lncRNA NEAT1 (Fig. 1B-e) (30,31). Lastly, BCLAF1 was found to be an important splicing factor to maintain the stability of $c-M y c$ mRNA expression in HCC (Fig. 1A and B-e) (39).

Given the subcellular localization of BCLAF1, most of the previous research found that BCLAF1 primarily localizes in the nucleus and in a small amount in the cytoplasm $(1,7,18)$. Under different conditions, the localization of BCLAF1 can change, which is accompanied by functional changes. For example, the anti-apoptotic members of the Bcl-2 family inhibit the pro-apoptotic effect of BCLAF1 by isolating BCLAF1 in the cytoplasm (1). Similarly, in apoptosis-induced cells, BCLAF1 is translocated to dot-like structures in the nucleus to exert its pro-apoptotic function (18). However, further research is required to reveal the association between the subcellular localization of BCLAF1 and its complex functions.

An increasing amount of evidence has shown that BCLAF1 can exert carcinogenic and antitumor effects in specific types of cancer and in a cell background-specific manner. For example, BCLAF1 has been found to plays a potential tumor suppressor effect in MM (21) and DLBCL (35), but has a tumor-promoting effect in $\operatorname{AML}(38), \operatorname{HCC}(30,31,37,39,42)$ and gastric cancer (11). Even in some tumor types (such as BC, LC and $\mathrm{CRC}$ ), it has been observed that BCLAF1 is both a tumor suppressor $(7,32,43)$ and a tumor promoter $(22,34,40,41)$. The reasons for this may be due to the tumor microenvironment or tumor heterogeneity, or differences in biological samples. Given multiple tumors are characterized by significant heterogeneity and complex microenvironment $(73,74,87)$, these studies may use different biological samples (human cancer tissues, tumor cell lines and animal models). In addition, the human $B C L A F 1$ gene encodes several transcriptional variants; therefore, the complex structure of the BCLAF1 protein itself may also mediate its complex and even contradictory effects in tumorigenesis. Thus, the specific mechanism requires further investigation to clarify its different roles. For example, the establishment of a systemic and tissue-specific BCLAF1 
gene knockout mouse model may provide a comprehensive understanding of the physiological and pathological functions of BCLAF1, particularly in tumorigenesis (121). In addition, attention should be paid to the role of BCLAF1 in pathological processes other than tumorigeneses, such as viral infection and cardiac I/R injury. Some progress has been made in the investigation into the role and mechanisms of BCLAF1 in virus infection; however, contradictory results have been observed. For example, BCLAF1 acted as a viral inhibitor in viral infections, such as KSHV, HCMV and PRV, but acted as a viral replication-promoting factor in HPV16 (13-16). Notably, BCLAF1 has recently been found to promote cardiac I/R injury by mediating cardiomyocyte apoptosis (23), which was the first time to associate the regulation of BCLAF1 in apoptosis with cardiac I/R injury.

Given the complex and even contradictory roles of BCLAF1 in tumorigenesis, BCLAF1 has been classified and discussed based on its roles in tumorigenesis to identify targets for specific therapy. In tumor types in which BCLAF1 acts as a tumor promoter (such as HCC and AML), the pathogenic pathway of BCLAF1 may be blocked by targeting some key signaling molecules. For example, targeted inhibition of HSP90, HIF-1 $\alpha$ and 1ncRNA NEAT1 in HCC may be considered, while in AML, upregulation of miR-194-5p could be considered. By contrast, in other tumor types in which BCLAF1 acts as a tumor suppressor (such as DLBCL and $\mathrm{MM}$ ), the anti-cancer pathway of BCLAF1 may be activated by targeting some key signaling molecules. For example, in DLBCL, inhibition of NF- $\kappa$ B may be effective, while in MM, caspase-10 could be inhibited. Of course, more in-depth research is required to determine the exact roles of BCLAF1 in tumorigenesis, particularly in different types of cancer with paradoxical effects of BCLAF1 (including BC, LC and CRC), thus making it possible to perform targeted therapy. Notably, although survival analysis of data from the GEPIA2 database showed established prognostic value of BCLAF1 in BC (high expression of BCLAF1 was associated with a less favorable prognosis) (Fig. 3B), there are no reports of the association between BCLAF1 and $\mathrm{BC}$; therefore, more studies into the mechanism of BCLAF1 in BC is required.

Taken together, in vitro, in vivo and studies using clinical samples have aided in the understanding of the role of BCLAF1 in the occurrence, progression and resistance of different types of cancer. As BCLAF1 plays an important role in key cancer-related signaling pathways, regulating the activity or abundance of this key molecule may provide a new therapeutic strategy for patients with cancer in the future.

\section{Acknowledgements}

Not applicable.

\section{Funding}

The present study was supported by the Natural Science Foundation of Zhejiang Province (grant no. LY20C070001), the Natural Science Foundation of Ningbo (grant nos. 202003N4197 and 2021J294), the National Natural Science Foundation of China (grant. no. 31801165) and the K.C. Wong Magna Fund in Ningbo University.

\section{Availability of data and materials}

The datasets used during the current study are available in the Human Protein Atlas (https://www.proteinatlas. org/ENSG00000029363-BCLAF1), GEPIA2 (http://gepia2. cancer-pku.cn/\#survival), ICGC (https://dcc.icgc. org/genes/ENSG00000029363) and the PROMO databases (http://alggen.lsi.upc.es/cgi-bin/promo_v3/promo/promoinit. cgi?dirDB=TF_8.3).

\section{Authors' contributions}

XJ and HL conceived the study. ZY and JZ drafted the manuscript. HW made substantial contributions to the interpretation, drafting the manuscript and revising it critically for important intellectual content. Data sharing is not applicable. All authors read and approved the final manuscript.

\section{Ethics approval and consent to participate}

Not applicable.

\section{Patient consent for publication}

Not applicable.

\section{Competing interests}

The authors declare that they have no competing interests.

\section{References}

1. Kasof GM, Goyal L and White E: Btf, a novel death-promoting transcriptional repressor that interacts with Bcl-2-related proteins. Mol Cell Biol 19: 4390-4404, 1999.

2. Bracken CP, Wall SJ, Barré B, Panov KI, Ajuh PM and Perkins ND: Regulation of cyclin D1 RNA stability by SNIP1. Cancer Res 68: 7621-7628, 2008.

3. Savage KI, Gorski JJ, Barros EM, Irwin GW, Manti L, Powell AJ, Pellagatti A, Lukashchuk N, McCance DJ, McCluggage WG, et al: Identification of a BRCA1-mRNA splicing complex required for efficient DNA repair and maintenance of genomic stability. Mol Cell 54: 445-459, 2014.

4. Vohhodina J, Barros EM, Savage AL, Liberante FG, MantiL, Bankhead P, Cosgrove N, Madden AF, Harkin DP and Savage KI: The RNA processing factors THRAP3 and BCLAF1 promote the DNA damage response through selective mRNA splicing and nuclear export. Nucleic Acids Res 45: 12816-12833, 2017.

5. Varia S, Cheedu D, Markey M, Torres-Shafer K, Battini VP, Bubulya A and Bubulya PA: Alignment of Mitotic Chromosomes in Human Cells Involves SR-Like Splicing Factors Btf and TRAP150. Int J Mol Sci 18: 1956, 2017.

6. Merz C, Urlaub H, Will CL and Lührmann R: Protein composition of human mRNPs spliced in vitro and differential requirements for mRNP protein recruitment. RNA 13: 116-128, 2007.

7. Lee YY, Yu YB, Gunawardena HP, Xie L and Chen X: BCLAF1 is a radiation-induced $\mathrm{H} 2 \mathrm{AX}$-interacting partner involved in $\gamma \mathrm{H} 2 \mathrm{AX}$-mediated regulation of apoptosis and DNA repair. Cell Death Dis 3: e359, 2012.

8. Shao AW, Sun H, Geng Y, Peng Q, Wang P, Chen J, Xiong T, Cao $\mathrm{R}$ and Tang $\mathrm{J}$ : Bclaf1 is an important $\mathrm{NF}-\kappa \mathrm{B}$ signaling transducer and $\mathrm{C} / \mathrm{EBP} \beta$ regulator in DNA damage-induced senescence. Cell Death Differ 23: 865-875, 2016.

9. Liu H, Lu ZG, Miki Y and Yoshida K: Protein kinase C delta induces transcription of the TP53 tumor suppressor gene by controlling death-promoting factor $\mathrm{Btf}$ in the apoptotic response to DNA damage. Mol Cell Biol 27: 8480-8491, 2007. 
10. Ma Z, Wang H, Meng F, Han Y, Chen Y, Xiao M, Jiang H, Yu Z and Xu B: Role of BCLAF-1 in PD-L1 stabilization in response to ionizing irradiation. Cancer Sci 112: 4064-4074, 2021.

11. Liu J, Li J, Sun Z, Duan Y, Wang F, Wei G and Yang JH: Bcl-2-associated transcription factor $1 \mathrm{Ser}^{290}$ phosphorylation mediates DNA damage response and regulates radiosensitivity in gastric cancer. J Transl Med 19: 339, 2021.

12. McPherson JP, Sarras H, Lemmers B, Tamblyn L, Migon E, Matysiak-Zablocki E, Hakem A, Azami SA, Cardoso R, Fish J, et al: Essential role for Bclaf1 in lung development and immune system function. Cell Death Differ 16: 331-339, 2009.

13. Lee SH, Kalejta RF, Kerry J, Semmes OJ, O'Connor CM, Khan Z, Garcia BA, Shenk T and Murphy E: BclAF1 restriction factor is neutralized by proteasomal degradation and microRNA repression during human cytomegalovirus infection. Proc Natl Acad Sci USA 109: 9575-9580, 2012.

14. Qin C, Zhang R, Lang Y, Shao A, Xu A, Feng W, Han J, Wang M, $\mathrm{He} W, \mathrm{Yu} C$, et al: Bclafl critically regulates the type I interferon response and is degraded by alphaherpesvirus US3. PLoS Pathog 15: e1007559, 2019.

15. Ziegelbauer JM, Sullivan CS and Ganem D: Tandem array-based expression screens identify host mRNA targets of virus-encoded microRNAs. Nat Genet 41: 130-134, 2009.

16. Nilsson K, Wu C and Schwartz S: Role of the DNA Damage Response in Human Papillomavirus RNA Splicing and Polyadenylation. Int J Mol Sci 19: 1735, 2018.

17. Meinke P, Nguyen TD and Wehnert MS: The LINC complex and human disease. Biochem Soc Trans 39: 1693-1697, 2011.

18. Haraguchi T, Holaska JM, Yamane M, Koujin T, Hashiguchi N, Mori C, Wilson KL and Hiraoka Y: Emerin binding to Btf, a death-promoting transcriptional repressor, is disrupted by a missense mutation that causes Emery-Dreifuss muscular dystrophy. Eur J Biochem 271: 1035-1045, 2004.

19. Lowe M, Lage J, Paatela E, Munson D, Hostager R, Yuan C, Katoku-Kikyo N, Ruiz-Estevez M, Asakura Y, Staats J, et al: Cry2 Is Critical for Circadian Regulation of Myogenic Differentiation by Bclaf1-Mediated mRNA Stabilization of Cyclin D1 and Tmem176b. Cell Rep 22: 2118-2132, 2018.

20. Wang Y, Li M, Wang Y, Liu J, Zhang M, Fang X, Chen H and ZhangC: A Zfp609 circular RNA regulates myoblast differentiation by sponging miR-194-5p. Int J Biol Macromol 121: 1308-1313, 2019.

21. Lamy L, Ngo VN, Emre NC, Shaffer AL III, Yang Y, Tian E, Nair V, Kruhlak MJ, Zingone A, Landgren O, et al: Control of autophagic cell death by caspase-10 in multiple myeloma. Cancer Cell 23: 435-449, 2013.

22. Shen B, Tan M, Mu X, Qin Y, Zhang F, Liu Y and Fan Y: Upregulated SMYD3 promotes bladder cancer progression by targeting BCLAF1 and activating autophagy. Tumour Biol 37: 7371-7381, 2016

23. Zhang Y, Zhang X, Cai B, Li Y, Jiang Y, Fu X, Zhao Y, Gao H, Yang Y, Yang J, et al: The long noncoding RNA lncCIR BIL disrupts the nuclear translocation of Bclaf1 alleviating cardiac ischemia-reperfusion injury. Nat Commun 12: 522, 2021

24. Kong S, Kim SJ, Sandal B, Lee SM, Gao B, Zhang DD and Fang D: The type III histone deacetylase Sirt1 protein suppresses p300-mediated histone $\mathrm{H} 3$ lysine 56 acetylation at Bclaf1 promoter to inhibit T cell activation. J Biol Chem 286: 16967-16975, 2011.

25. Jarboui MA, Wynne K, Elia G, Hall WW and Gautier VW: Proteomic profiling of the human T-cell nucleolus. Mol Immunol 49: 441-452, 2011.

26. Philipps D, Celotto AM, Wang QQ, Tarng RS and Graveley BR: Arginine/serine repeats are sufficient to constitute a splicing activation domain. Nucleic Acids Res 31: 6502-6508, 2003.

27. Schaal TD and Maniatis T: Multiple distinct splicing enhancers in the protein-coding sequences of a constitutively spliced pre-mRNA. Mol Cell Biol 19: 261-273, 1999.

28. Smith CW and Valcárcel J: Alternative pre-mRNA splicing: The logic of combinatorial control. Trends Biochem Sci 25: 381-388, 2000 .

29. Sarras H, Alizadeh Azami S and McPherson JP: In search of a function for BCLAF1. ScientificWorldJournal 10: 1450-1461, 2010

30. Wen Y, Zhou X, Lu M, He M, Tian Y, Liu L, Wang M, Tan W, Deng Y, Yang X, et al: Bclaf1 promotes angiogenesis by regulating HIF-1 $\alpha$ transcription in hepatocellular carcinoma. Oncogene 38: 1845-1859, 2019

31. Mou SJ, Yang PF, Liu YP, Xu N, Jiang WW and Yue WJ: BCLAF1 promotes cell proliferation, invasion and drug-resistance though targeting lncRNA NEAT1 in hepatocellular carcinoma. Life Sci 242: 117177, 2020
32. Rénert AF, Leprince P, Dieu M, Renaut J, Raes M, Bours V, Chapelle JP, Piette J, Merville MP and Fillet M: The proapoptotic C16-ceramide-dependent pathway requires the death-promoting factor Btf in colon adenocarcinoma cells. J Proteome Res 8: 4810-4822, 2009.

33. Orieux G, Picault L, Slembrouck A, Roger JE, Guillonneau X, Sahel JA, Saule S, McPherson JP and Goureau O: Involvement of Bcl-2-associated transcription factor 1 in the differentiation of early-born retinal cells. J Neurosci 34: 1530-1541, 2014.

34. Zhou X, Li X, Cheng Y, Wu W, Xie Z, Xi Q, Han J, Wu G, Fang J and Feng Y: BCLAF1 and its splicing regulator SRSF10 regulate the tumorigenic potential of colon cancer cells. Nat Commun 5: 4581,2014

35. Li X, He Z, Cheng B, Fang Q, Ma D, Lu T, Wei D, Kuang X, Tang S, Xiong J, et al: Effect of BCLAF1 on HDAC inhibitor LMK-235-mediated apoptosis of diffuse large B cell lymphoma cells and its mechanism. Cancer Biol Ther 19: 825-834, 2018

36. Chen M, Zhang R, Lu L, Du J, Chen C, Ding K, Wei X, Zhang G, Huang Y and Hou J: lncRNA PVT1 accelerates malignant phenotypes of bladder cancer cells by modulating miR-194-5p/BCLAF1 axis as a ceRNA. Aging (Albany NY) 12: 22291-22312, 2020.

37. Yu S, Wang X, Dou N, Zhou J, Gao Y and Li Y: B-cell lymphoma-2-associated transcription factor 1 is overexpressed and contributes to sorafenib resistance in hepatocellular carcinoma. Hepatol Res 49: 1329-1340, 2019.

38. Dell'Aversana C, Giorgio C, D'Amato L, Lania G, Matarese F, Saeed S, Di Costanzo A, Belsito Petrizzi V, Ingenito C, Martens JHA, et al: miR-194-5p/BCLAF1 deregulation in AML tumorigenesis. Leukemia 31: 2315-2325, 2017.

39. Zhou X, Wen Y, Tian Y, He M, Ke X, Huang Z, He Y, Liu L, Scharf A, Lu M, et al: Heat Shock Protein 90a-Dependent B-Cell-2-Associated Transcription Factor 1 Promotes Hepatocellular Carcinoma Proliferation by Regulating MYC Proto-Oncogene c-MYC mRNA Stability. Hepatology 69: 1564-1581, 2019.

40. Wang X, Wei X, Yuan Y, Sun Q, Zhan J, Zhang J, Tang Y, Li F, Ding L, Ye Q, et al: Src-mediated phosphorylation converts FHL1 from tumor suppressor to tumor promoter. J Cell Biol 217: 1335-1351, 2018

41. Jiang T, Liu B, Wu D and Zhang F: BCLAF1 induces cisplatin resistance in lung cancer cells. Oncol Lett 20: 227, 2020.

42. Zhang S, Zhang M, Chen J, Zhao J, Su J and Zhang X: Ginsenoside Compound K Regulates HIF-1 $\alpha$-Mediated Glycolysis Through Bclaf1 to Inhibit the Proliferation of Human Liver Cancer Cells. Front Pharmacol 11: 583334, 2020

43. Yoshitomi T, Kawakami K, Enokida H, Chiyomaru T, Kagara I, Tatarano S, Yoshino H, Arimura H, Nishiyama K, Seki N, et al: Restoration of miR-517a expression induces cell apoptosis in bladder cancer cell lines. Oncol Rep 25: 1661-1668, 2011.

44. The National Center for Biotechnology Information [OL]: BCLAF1 BCL2 associated transcription factor 1 [Homo sapiens (human) ]. https://www.ncbi.nlm.nih.gov/gene/9774, Accessed November 7, 2021.

45. Black DL: Mechanisms of alternative pre-messenger RNA splicing. Annu Rev Biochem 72: 291-336, 2003.

46. Wahl MC, Will CL and Lührmann R: The spliceosome: Design principles of a dynamic RNP machine. Cell 136: 701-718, 2009.

47. Wu JY and Maniatis T: Specific interactions between proteins implicated in splice site selection and regulated alternative splicing. Cell 75: 1061-1070, 1993.

48. Kohtz JD, Jamison SF, Will CL, Zuo P, Lührmann R, Garcia-Blanco MA and Manley JL: Protein-protein interactions and 5'-splice-site recognition in mammalian mRNA precursors. Nature 368: 119-124, 1994.

49. Ramsay RG and Gonda TJ: MYB function in normal and cancer cells. Nat Rev Cancer 8: 523-534, 2008.

50. Shaulian E and Karin M: AP-1 as a regulator of cell life and death. Nat Cell Biol 4: E131-E136, 2002 .

51. Nerlov C: The C/EBP family of transcription factors: A paradigm for interaction between gene expression and proliferation control. Trends Cell Biol 17: 318-324, 2007.

52. Bartel DP: MicroRNAs: Target recognition and regulatory functions. Cell 136: 215-233, 2009.

53. LaGory EL and Giaccia AJ: The ever-expanding role of HIF in tumour and stromal biology. Nat Cell Biol 18: 356-365, 2016.

54. Keith B, Johnson RS and Simon MC: HIF1 $\alpha$ and HIF2 $\alpha$ : Sibling rivalry in hypoxic tumour growth and progression. Nat Rev Cancer 12: 9-22, 2011 
55. Shao A, Lang Y, Wang M, Qin C, Kuang Y, Mei Y, Lin D, Zhang S and Tang J: Bclaf1 is a direct target of HIF-1 and critically regulates the stability of HIF-1 $\alpha$ under hypoxia. Oncogene 39: 2807-2818, 2020.

56. Liu F, Tai Y and Ma J: 1ncRNA NEAT1/let-7a-5p axis regulates the cisplatin resistance in nasopharyngeal carcinoma by targeting Rsf- 1 and modulating the Ras-MAPK pathway. Cancer Biol Ther 19: 534-542, 2018

57. Zhang J, Zhao B, Chen X, Wang Z, Xu H and Huang B: Silence of Long Noncoding RNA NEAT1 Inhibits Malignant Biological Behaviors and Chemotherapy Resistance in Gastric Cancer. Pathol Oncol Res 24: 109-113, 2018.

58. An J, Lv W and Zhang Y: IncRNA NEAT1 contributes to paclitaxel resistance of ovarian cancer cells by regulating ZEB1 expression via miR-194. OncoTargets Ther 10: 5377-5390, 2017.

59. Maloney A and Workman P: HSP90 as a new therapeutic target for cancer therapy: The story unfolds. Expert Opin Biol Ther 2: $3-24,2002$.

60. Sirvent N, Imbert V, Frelin C, Griessinger E and Peyron JF: Fighting cancer via NF-kappa B inhibition. Arch Pediatr 10 632-634, 2003 (In French).

61. Haefner B: NF- $\kappa$ B: Arresting a major culprit in cancer. Drug Discov Today 7: 653-663, 2002.

62. Barkett M and Gilmore TD: Control of apoptosis by Rel/NF-kappaB transcription factors. Oncogene 18: 6910-6924, 1999.

63. Karin M, Cao Y, Greten FR and Li Z-W: NF-kappaB in cancer: From innocent bystander to major culprit. Nat Rev Cancer 2: 301-310, 2002

64. Karin M and Lin A: NF-kappaB at the crossroads of life and death. Nat Immunol 3: 221-227, 2002.

65. Wilson GK, Tennant DA and McKeating JA: Hypoxia inducible factors in liver disease and hepatocellular carcinoma: Current understanding and future directions. J Hepatol 61: 1397-1406, 2014.

66. Kim DY, Yuan HD, Chung IK and Chung SH: Compound K intestinal metabolite of ginsenoside, attenuates hepatic lipid accumulation via AMPK activation in human hepatoma cells. J Agric Food Chem 57: 1532-1537, 2009.

67. Bray F, Ferlay J, Soerjomataram I, Siegel RL, Torre LA and Jemal A: Global cancer statistics 2018: GLOBOCAN estimates of incidence and mortality worldwide for 36 cancers in 185 countries. CA Cancer J Clin 68: 394-424, 2018.

68. Luo M, Li Z, Wang W, Zeng Y, Liu Z and Qiu J: Long non-coding RNA H19 increases bladder cancer metastasis by associating with EZH2 and inhibiting E-cadherin expression. Cancer Lett 333: 213-221, 2013

69. Varier RA and Timmers HT: Histone lysine methylation and demethylation pathways in cancer. Biochim Biophys Acta 1815 75-89, 2011.

70. Bian Y, Li W, Kremer DM, Sajjakulnukit P, Li S, Crespo J, Nwosu ZC, Zhang L, Czerwonka A, Pawłowska A, et al: Cancer SLC43A2 alters T cell methionine metabolism and histone methylation. Nature 585: 277-282, 2020.

71. Luo XG, Zhang CL, Zhao WW, Liu ZP, Liu L, Mu A, Guo S, Wang N, Zhou $\mathrm{H}$ and Zhang TC: Histone methyltransferase SMYD3 promotes MRTF-A-mediated transactivation of MYL9 and migration of MCF-7 breast cancer cells. Cancer Lett 344: 129-137, 2014

72. Fenizia C, Bottino C, Corbetta S, Fittipaldi R, Floris P, Gaudenzi G, Carra S, Cotelli F, Vitale G and Caretti G: SMYD3 promotes the epithelial-mesenchymal transition in breast cancer. Nucleic Acids Res 47: 1278-1293, 2019.

73. Pattingre S, Tassa A, Qu X, Garuti R, Liang XH, Mizushima N, Packer M, Schneider MD and Levine B: Bcl-2 antiapoptotic proteins inhibit Beclin 1-dependent autophagy. Cell 122 927-939, 2005.

74. da Costa JB, Gibb EA, Nykopp TK, Mannas M, Wyatt AW and Black PC: Molecular tumor heterogeneity in muscle invasive bladder cancer: Biomarkers, subtypes, and implications for therapy. Urol Oncol 2018: S1078-1439(18)30463-0, 2018.

75. Sung H, Ferlay J, Siegel RL, Laversanne M, Soerjomataram I, Jemal A and Bray F: Global Cancer Statistics 2020: GLOBOCAN Estimates of Incidence and Mortality Worldwide for 36 Cancers in 185 Countries. CA Cancer J Clin 71: 209-249, 2021.

76. Burma S, Chen BP and Chen DJ: Role of non-homologous end joining (NHEJ) in maintaining genomic integrity. DNA Repair (Amst) 5: 1042-1048, 2006

77. Wang Q, Gao F, Wang T, Flagg T and Deng X: A nonhomologous end-joining pathway is required for protein phosphatase $2 \mathrm{~A}$ promotion of DNA double-strand break repair. Neoplasia 11: 1012-1021, 2009
78. Li Z, Owonikoko TK, Sun SY, Ramalingam SS, Doetsch PW, Xiao ZQ, Khuri FR, Curran WJ and Deng X: c-Myc suppression of DNA double-strand break repair. Neoplasia 14: 1190-1202, 2012.

79. Niu C, Liang C, Guo J, Cheng L, Zhang H, Qin X, Zhang Q, Ding L, Yuan B, Xu X, et al: Downregulation and growth inhibitory role of FHL1 in lung cancer. Int J Cancer 130: 2549-2556, 2012.

80. Ding L, Wang Z, Yan J, Yang X, Liu A, Qiu W, Zhu J, Han J, Zhang H, Lin J, et al: Human four-and-a-half LIM family members suppress tumor cell growth through a TGF-beta-like signaling pathway. J Clin Invest 119: 349-361, 2009.

81. Ding L, Niu C, Zheng Y, Xiong Z, Liu Y, Lin J, Sun H, Huang K, Yang W, Li X, et al: FHL1 interacts with oestrogen receptors and regulates breast cancer cell growth. J Cell Mol Med 15: 72-85, 2011.

82. Xu X, Fan Z, Liang C, Li L, Wang L, Liang Y, Wu J, Chang S, Yan Z, Lv Z, et al: A signature motif in LIM proteins mediates binding to checkpoint proteins and increases tumour radiosensitivity. Nat Commun 8: 14059, 2017

83. Fennell DA, Summers Y, Cadranel J, Benepal T, Christoph DC, Lal R, Das M, Maxwell F, Visseren-Grul C and Ferry D: Cisplatin in the modern era: The backbone of first-line chemotherapy for non-small cell lung cancer. Cancer Treat Rev 44: 42-50, 2016.

84. Perše M and Večerić-Haler Ž: Cisplatin-Induced Rodent Model of Kidney Injury: Characteristics and Challenges. BioMed Res Int 2018: 1462802, 2018.

85. Dasari S and Tchounwou PB: Cisplatin in cancer therapy: Molecular mechanisms of action. Eur J Pharmacol 740: 364-378, 2014.

86. Wang A, Ning Z, Lu C, Gao W, Liang J, Yan Q, Tan G and Liu J: USP22 Induces Cisplatin Resistance in Lung Adenocarcinoma by Regulating $\gamma \mathrm{H} 2 \mathrm{AX}$-Mediated DNA Damage Repair and Ku70/Bax-Mediated Apoptosis. Front Pharmacol 8: 274, 2017.

87. Park $\mathrm{CH}$, Eun CS and Han DS: Intestinal microbiota, chronic inflammation, and colorectal cancer. Intest Res 16: 338-345, 2018.

88. Kulik L and El-Serag HB: Epidemiology and management of hepatocellular carcinoma. Gastroenterology 156: 477-491.e1, 2019.

89. Burns JS and Manda G: Metabolic Pathways of the Warburg Effect in Health and Disease: Perspectives of Choice, Chain or Chance. Int J Mol Sci 18: 2755, 2017.

90. Yu L, Chen X, Sun X, Wang L and Chen S: The Glycolytic Switch in Tumors: How Many Players Are Involved? J Cancer 8: 3430-3440, 2017

91. Turesson I, Bjorkholm M, Blimark CH, Kristinsson S, Velez R and Landgren O: Rapidly changing myeloma epidemiology in the general population: Increased incidence, older patients, and longer survival. Eur J Haematol 101: 237-244, 2018.

92. Wang J, Chun HJ, Wong W, Spencer DM and Lenardo MJ: Caspase-10 is an initiator caspase in death receptor signaling. Proc Natl Acad Sci USA 98: 13884-13888, 2001.

93. Horn S, Hughes MA, Schilling R, Sticht C, Tenev T, Ploesser M, Meier P, Sprick MR, MacFarlane M and Leverkus M: Caspase-10 Negatively Regulates Caspase-8-Mediated Cell Death, Switching the Response to CD95L in Favor of NF- $\kappa$ B Activation and Cell Survival. Cell Rep 19: 785-797, 2017.

94. Caimi PF, Hill BT, Hsi ED and Smith MR: Clinical approach to diffuse large B cell lymphoma. Blood Rev 30: 477-491, 2016.

95. Mensah AA, Kwee I, Gaudio E, Rinaldi A, Ponzoni M, Cascione L, Fossati G, Stathis A, Zucca E, Caprini G, et al: Novel HDAC inhibitors exhibit pre-clinical efficacy in lymphoma models and point to the importance of CDKN1A expression levels in mediating their anti-tumor response. Oncotarget 6: 5059-5071, 2015

96. Ganai SA: Histone deacetylase inhibitor givinostat: The small-molecule with promising activity against therapeutically challenging haematological malignancies. J Chemother 28: 247-254, 2016.

97. Adams CM, Hiebert SW and Eischen CM: Myc Induces miRNA-Mediated Apoptosis in Response to HDAC Inhibition in Hematologic Malignancies. Cancer Res 76: 736-748, 2016.

98. Marek L, Hamacher A, Hansen FK, Kuna K, Gohlke H, Kassack MU and Kurz T: Histone deacetylase (HDAC) inhibitors with a novel connecting unit linker region reveal a selectivity profile for HDAC4 and HDAC5 with improved activity against chemoresistant cancer cells. J Med Chem 56: 427-436, 2013.

99. Culp-Hill R, D'Alessandro A and Pietras EM: Extinguishing the Embers: Targeting AML Metabolism. Trends Mol Med 27: 332-344, 2021 
100. Safi S, Beckhove P, Warth A, Benner A, Roeder F, Rieken S, Debus J, Dienemann H, Hoffmann H and Huber PE: A randomized phase II study of radiation induced immune boost in operable non-small cell lung cancer (RadImmune trial). BMC Cancer 15: 988, 2015.

101. Baidoo KE, Yong K and Brechbiel MW: Molecular pathways: Targeted $\alpha$-particle radiation therapy. Clin Cancer Res 19: 530-537, 2013

102. Matsuoka S, Ballif BA, Smogorzewska A, McDonald ER III, Hurov KE, Luo J, Bakalarski CE, Zhao Z, Solimini N, Lerenthal Y, et al: ATM and ATR substrate analysis reveals extensive protein networks responsive to DNA damage. Science 316: 1160-1166, 2007.

103. Keir ME, Liang SC, Guleria I, Latchman YE, Qipo A Albacker LA, Koulmanda M, Freeman GJ, Sayegh MH and Sharpe AH: Tissue expression of PD-L1 mediates peripheral T cell tolerance. J Exp Med 203: 883-895, 2006.

104. Schreiner B, Bailey SL, Shin T, Chen L and Miller SD: PD-1 ligands expressed on myeloid-derived APC in the CNS regulate T-cell responses in EAE. Eur J Immunol 38: 2706-2717, 2008.

105. Antonia SJ, Villegas A, Daniel D, Vicente D, Murakami S, Hui R, Kurata T, Chiappori A, Lee $\mathrm{KH}$, de Wit M, et al; PACIFIC Investigators: Overall survival with durvalumab after chemoradiotherapy in stage III NSCLC. N Engl J Med 379: 2342-2350, 2018.

106. Shaverdian N, Lisberg AE, Bornazyan K, Veruttipong D, Goldman JW, Formenti SC, Garon EB and Lee P: Previous radiotherapy and the clinical activity and toxicity of pembrolizumab in the treatment of non-small-cell lung cancer: A secondary analysis of the KEYNOTE-001 phase 1 trial. Lancet Oncol 18: 895-903, 2017

107. Chang Y, Cesarman E, Pessin MS, Lee F, Culpepper J, Knowles DM and Moore PS: Identification of herpesvirus-like DNA sequences in AIDS-associated Kaposi's sarcoma. Science 266: 1865-1869, 1994.

108. 1Gao SJ, Kingsley L, Hoover DR, Spira TJ, Rinaldo CR, Saah A, Phair J, Detels R, Parry P, Chang Y, et al: Seroconversion to antibodies against Kaposi's sarcoma-associated herpesvirus-related latent nuclear antigens before the development of Kaposi's sarcoma. N Engl J Med 335: 233-241, 1996.

109. Cesarman E, Chang Y, Moore PS, Said JW and Knowles DM: Kaposi's sarcoma-associated herpesvirus-like DNA sequences in AIDS-related body-cavity-based lymphomas. N Engl J Med 332: 1186-1191, 1995.
110. Soulier J, Grollet L, Oksenhendler E, Cacoub P, Cazals-Hatem D, Babinet P, d'Agay MF, Clauvel JP, Raphael M, Degos L, et al: Kaposi's sarcoma-associated herpesvirus-like DNA sequences in multicentric Castleman's disease. Blood 86: 1276-1280, 1995.

111. Boshoff $C$ and Weiss R: AIDS-related malignancies. Nat Rev Cancer 2: 373-382, 2002.

112. Griffante G, Gugliesi F, Pasquero S, Dell'Oste V, Biolatti M, Salinger AJ, Mondal S, Thompson PR, Weerapana E, Lebbink RJ, et al: Human cytomegalovirus-induced host protein citrullination is crucial for viral replication. Nat Commun 12: 3910,2021

113. Halenius A and Hengel H: Human cytomegalovirus and autoimmune disease. BioMed Res Int 2014: 472978, 2014.

114. Herbein G: The Human Cytomegalovirus, from Oncomodulation to Oncogenesis. Viruses 10: 408, 2018.

115. Sadler AJ and Williams BR: Interferon-inducible antiviral effectors. Nat Rev Immunol 8: 559-568, 2008

116. zur Hausen H: Papillomaviruses and cancer: From basic studies to clinical application. Nat Rev Cancer 2: 342-350, 2002.

117. You J, Srinivasan V, Denis GV, Harrington WJ Jr, Ballestas ME, Kaye KM and Howley PM: Kaposi's sarcoma-associated herpesvirus latency-associated nuclear antigen interacts with bromodomain protein Brd4 on host mitotic chromosomes. J Virol 80: 8909-8919, 2006

118. Eltzschig HK and Eckle T: Ischemia and reperfusion--from mechanism to translation. Nat Med 17: 1391-1401, 2011

119. Kalogeris T, Baines CP, Krenz M and Korthuis RJ: Ischemia/Reperfusion. Compr Physiol 7: 113-170, 2016.

120. Diella F, Cameron S, Gemünd C, Linding R, Via A, Kuster B, Sicheritz-Pontén T, Blom N and Gibson TJ: Phospho.ELM: A database of experimentally verified phosphorylation sites in eukaryotic proteins. BMC Bioinformatics 5: 79, 2004.

121. Wang Z, Song Y, Ye M, Dai X, Zhu X and Wei W: The diverse roles of SPOP in prostate cancer and kidney cancer. Nat Rev Urol 17: 339-350, 2020

(i) $\mathrm{C}$ This work is licensed under a Creative Commons Attribution-NonCommercial-NoDerivatives 4.0 International (CC BY-NC-ND 4.0) License. 